Portland State University

PDXScholar

Fall 12-19-2012

\title{
Use of International Hydrographic Organization Tidal Data for Improved Tidal Prediction
}

Songwei Qi

Portland State University

Follow this and additional works at: https://pdxscholar.library.pdx.edu/open_access_etds

Part of the Oceanography Commons, and the Other Civil and Environmental Engineering Commons Let us know how access to this document benefits you.

\section{Recommended Citation}

Qi, Songwei, "Use of International Hydrographic Organization Tidal Data for Improved Tidal Prediction" (2012). Dissertations and Theses. Paper 900.

https://doi.org/10.15760/etd.900

This Thesis is brought to you for free and open access. It has been accepted for inclusion in Dissertations and Theses by an authorized administrator of PDXScholar. Please contact us if we can make this document more accessible: pdxscholar@pdx.edu. 
Use of International Hydrographic Organization Tidal Data

for Improved Tidal Prediction

by

Songwei Qi

A thesis submitted in partial fulfillment of the requirements for the degree of

\author{
Master of Science \\ in \\ Civil and Environmental Engineering
}

Thesis Committee:

Edward D. Zaron, Chair

David A. Jay

Scott A. Wells

Portland State University

2012 
(C) 2012 Songwei Qi 


\begin{abstract}
Tides are the rise and fall of water level caused by gravitational forces exerted by the sun, moon and earth. Understanding sea level variation and its impact on currents is very important especially in coastal regions. With knowledge of the tide-generating force and boundary conditions, hydrodynamic models can be used to predict or model tides in coastal regions. However, these models are not sufficiently accurate, and in-situ tide gauge data may be used to improve them in coastal regions. The International Hydrographic Organization (IHO) tidal data bank consists of over 4000 tide gauge stations scattered all around the globe, most of which are in coastal regions. These tide gauge data are very valuable for tidal predictions. One drawback of the IHO data is that a considerable number of stations are located in rivers or near man-made structures or small-scale, complex topographic features. Another drawback is the unknown accuracy of the IHO data. To avoid these drawbacks, quality control has been done in the present study. Each IHO tide gauge station has been categorized according to its proximity to rivers, lagoons, man-made harbors, and other factors that may influence tidal elevation. Quantitative metrics such as water depth, distance to the continental shelf break, and horizontal length scale of station site morphology have been computed. Comparisons among IHO data, the output of O.S.U. Tidal Inversion Software (OTIS), and other data sources, such as Global Sea-Level Observing System (GLOSS) data, have been done to
\end{abstract}


test the quality and accuracy of IHO data. Moreover, the characteristics of stations with large error have also been examined. The good comparison of IHO with duplicate GLOSS stations shows that, as far as can be determined, IHO data are reliable and ought to be used in improving coastal tide models. The non-Gaussian character of the errors suggests that further improvements in tidal modeling will require advances in data assimilation which are robust to non-Gaussian data error. 


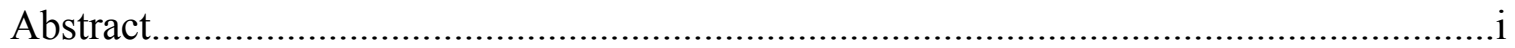

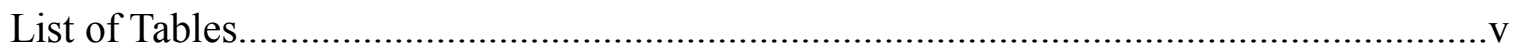

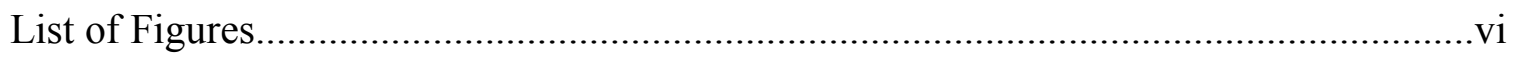

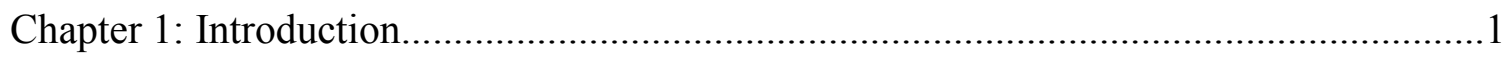

1.1. Motivation and Objectives.................................................................... 1

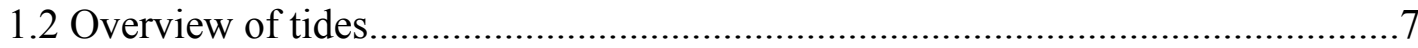

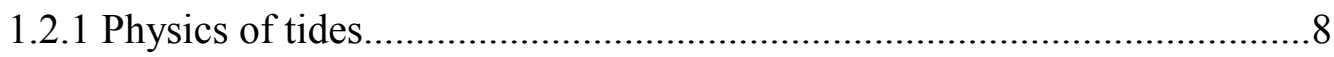

1.2.2 Tidal Species......................................................................... 12

1.2.3 Classical Tidal Analysis and Tidal Constituents..................................12

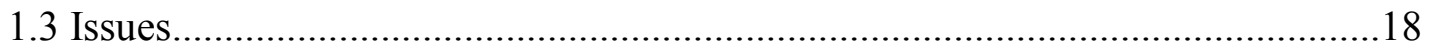

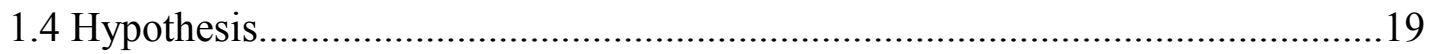

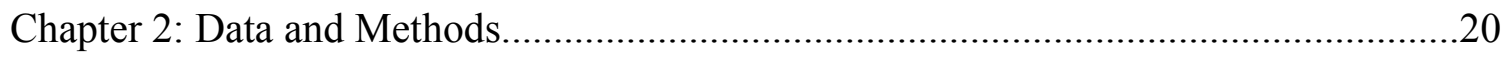

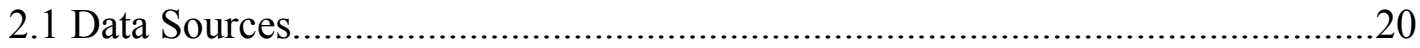

2.2 Quality Control in Google Earth..................................................................26

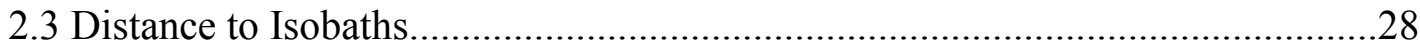

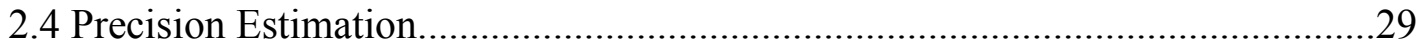

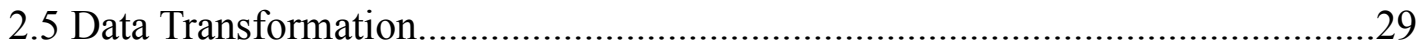

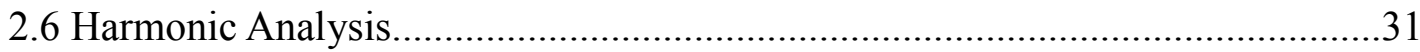

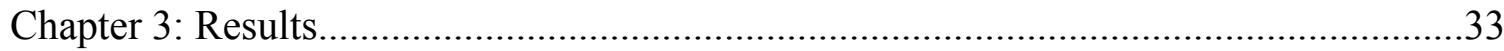


3.1 GLOSS, IHO, OTIS pair wise comparison.

References... 


\section{List of Tables}

Table 1 Basic periods and frequencies of astronomical motions....................................16

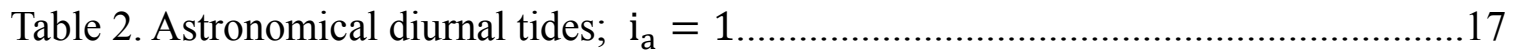

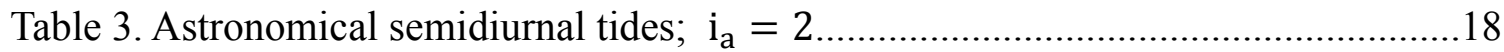

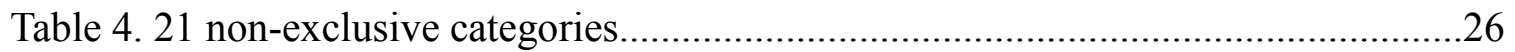

Table 5. RMS misfit: TPXO7.2 output vs IHO stations, GLOSS stations, GLOSS

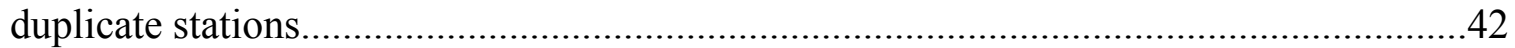

Table 6 relative differences: GLOSS duplicate stations vs GLOSS stations....................42

Table 7. RMS misfit: GLOSS duplicate stations vs GLOSS stations..............................43

Table 8. Scale parameters of Laplace and Cauchy distribution......................................46 


\section{List of Figures}

Figure 1. Diagram to show the location of the selected general point $\mathrm{P}$ on the earth surface

Figure 2. The relationship between the equilibrium water surface, the tide generating force, and the normal earth's gravity force

Figure 3. IHO station distribution

Figure 4. GLOSS tide gauge distribution.

.22

Figure 5. A typical river-estuary-mouth station distribution in Tagus River, Portugal. Red segments are defined characteristic length scale. Yellow pins are IHO stations, red pins are GLOSS stations. .23

Figure 6. TPXO7.2 M2 amplitude solution 25

Figure 7. Matlab GUI created for editing IHO data .30

Figure 8. Top: histogram of IHO station distribution on distance to coastline. Bottom: histogram of IHO station distribution on number of tidal constituents 34

Figure 9. M2 amplitude difference between IHO data and OTIS output vs length scale.

Figure 10. M2 amplitude from OTIS output vs IHO data. Top: stations categorized "open ocean". Bottom: stations that are not "open ocean" 37

Figure 11. Number of tide gauges: amplitude difference vs distance to $200 \mathrm{~m}$ isobath 
Figure 12. Histogram of station distribution on length scale. Top: IHO stations. Bottom: GLOSS stations

Figure 13. Length of record comparisons. Blue line is the error resulted from harmonically analyzing different length of time series. The time length is shown on the $\mathrm{x}$ axis. Red line is the amplitude difference.

Figure 14. Top: Histogram of M2 relative error distribution and probability distribution plot. Bottom: Cumulative distribution plot. Red line is Gaussian distribution, green line is Laplace distribution, black line is Cauchy distribution. .47

Figure 15. Top: Histogram of M2 relative error distribution and probability distribution plot. Bottom Cumulative distribution plot. Red line is Gaussian distribution, green line is Laplace distribution, black line is Cauchy distribution. 48

Figure 16. Locations of large error stations (outliers of top: 96\% confidence interval, middle: $90 \%$ confidence interval, bottom: $85 \%$ confidence interval), shown in red dot...50 Figure 17. Top: M2 amplitude of IHO stations. Middle: absolute M2 amplitude difference between IHO and OTIS. Bottom: relative M2 amplitude difference between IHO and OTIS. 


\section{Chapter 1: Introduction}

\subsection{Motivation and Objectives}

The tide is a periodical movement in the level of the surface of the sea or ocean, due to periodical forces (Doodson, 1941). The study of tides is an old topic. The tide generating forces due to the gravitation of the sun, moon and earth can be precisely calculated. However, when the water becomes shallow, for example in coastal areas, non-astronomical factors such as the configuration of coastline, local bathymetry, river effects and meteorological effects become more and more important. Tides are therefore important to consider in many disciplines. Moreover, tides are important components of sea level undulation and coastal currents.

Tides play an important role in marine ecosystems. The species that live between high tide and low tide lines are mostly affected by tides. Their habitat is exposed to the atmosphere at low tide, and is underwater at high tide. Because of the regular periods of immersion and emersion, the intertidal species have evolved certain types of adaptive strategies. Some connections between tides and the reproductive behavior of marine species are well documented. For example, female sea turtles, horseshoe crabs and grunions can place fertilized eggs in the sand far enough from the coastline on a beach during spring tide to avoid the threat of predators (Segar, 1998).

Tide is also an important source of renewable energy. The energy of tides is 
dissipated by friction both in the seafloor and between different water masses (Segar, 1998). Some of the energy can be captured by electricity-generating turbines where the speed of tidal currents are sufficiently strong. The renewable energy produced from tidal power would lessen the greenhouse effect and environmental acidification that were caused by burning fossil fuels.

Tides are also important for coastal navigation. The tide is an important factor in water level variation especially in shallow regions. Navigation regulation requires the keel of a ship to be some meters above the bottom of the channel. This makes some areas inaccessible when there is neap tide combined with low flow condition. As a result, knowing local tidal level is one of the several pieces of key information for pilots to guide ships. Pilots usually sail their ship with the tide landward during spring tide period and seaward during high river flow period, accordingly (Brown, 2009).

Tides are an important topic in science. Understanding and quantitatively determining the ocean tides has been the goal of many outstanding mathematicians and physicists. Accurately estimating tide is important in several research fields. When measuring the gravity field, tide is a major source of gravity variation (Ray, 2003). What's more, the tidal signal often aliases within the raw satellite signal. As a result, to accurately estimate the gravity field, the tidal signal needs to be filtered out. The NASA TOPEX/Poseidon mission measured relative high resolution altimetry (sea surface height) around the globe, which will be used to study global ocean circulation and marine 
geophysics. It is necessary to remove ocean tides as well, which are aliased in the raw data (Egbert et al., 1994).

From open ocean to coastal regions, the tidal range generally becomes larger. The reason is that tides are long waves which propagate with speed, approximately, $\sqrt{\mathrm{gH}}$, where $\mathrm{g}$ is the gravitational acceleration and $\mathrm{H}$ is water depth. As waves approach shallow regions, their speeds decrease due to the decreased water depth and due to relatively larger bottom friction. To conserve total energy, the wave height may increase to compensate for the decreasing velocity. New waves generated by nonlinearity are called overtides. Moreover, if the disturbance at a coastal region is the result of two sinusoidal signals of frequencies $\omega_{1}$ and $\omega_{2}$, it is expected that constituents of frequencies $\mathrm{k}_{1} \omega_{1}+\mathrm{k}_{2} \omega_{2}$ will appear in the signal (with $\mathrm{k}_{1}$ and $\mathrm{k}_{1}$ positive, negative or null integers), which are known as compound tides (Le Provost, 1991). Overtides and compound tides in shallow regions are due to non-linear mechanisms, which often cannot be accurately simulated in numerical models.

River channel configuration and bottom topography also have large effects on tidal long wave propagation. Green (1838) states that tidal long wave elevation and tidal transport vary following power laws in an indefinitely extended canal of small breadth and depth with weak topography and no mean flow. Jay (1991) derived two solutions different from Green's Law for channel flow, including the effects of friction, smooth topography of arbitrary along channel scale, finite amplitude, river flow and tidal flats 
that store water but do not convey momentum. The two solutions are derived for weakly dissipative estuary and strongly dissipative estuary, respectively. Friedrichs and Aubrey (1994) studied the case of strongly convergent shallow estuaries. They suggested that estuaries are dynamically dominated by friction and kinematically dominated by convergence. Lanzoni and Seminara (1998) discussed four limiting cases for one-dimensional tide propagation in convergent estuaries. The four cases were defined by the relative intensity of dissipation versus local inertia in the momentum equation and by the role of channel convergence in the mass balance.

In the open ocean, the tidal spectrum can normally be represented by a limited number of well-defined astronomical frequencies, primarily in the diurnal and semidiurnal bands. However, in the coastal region, the tide is more complex. The distortions of the normal harmonic variations of tidal levels and currents due to bottom friction and other physical processes can be represented by an addition of higher harmonics. The higher harmonics have the frequencies in the long period, diurnal, semidiurnal, terdiurnal, and higher tide bands (Pugh, 1987).

Although satellite altimetry data can be used in tidal models to accurately estimate tide in the open ocean, the error is still large in coastal regions. In the coastal regions where shallow water tides play an important role in the entire tide signal, the signal to noise level is unfavorable because shallow water tides generally have small amplitudes. Another point that can cause problems is the large distance between satellite 
ground-tracks, which may not resolve the spatial scales of coastal tides. The temporal interval between two satellite measurements is also large compared to any tide gauges (Fu \& Cazenave, 2000). As a result, it is hard to conduct any analysis in a coastal area without in-situ measurements (Egbert et al., 1994).

Forecasting of tidal water elevation has traditionally been done through the use of tide tables developed from historical water level or tide stations measurements. Historical data are used to compute the amplitude and phase of tidal constituents, which, once known, can be used to predict water level at any future time. But the tides vary along the coastline, and in order to make predictions at sites where no tide stations have ever existed, numerical ocean models are used. The typical approach involves using a high-resolution (e.g., $1 \mathrm{~km}$ ) coastal model which is forced by tidal elevations at its open boundary (Parker et al, 1999).

Since the advent of satellite altimetry in the early 1990s, tides are now known with great precision in the deep ocean, and global tide models can provide deep-water open boundary conditions with an accuracy of nearly $1 \mathrm{~cm}$ over much of the globe (Lyard et al., 2006). Even with accurate boundary conditions, the accuracy of high-resolution coastal tide models is typically not better than $15 \mathrm{~cm}$.

Some improvement to coastal models can be achieved through improved bathymetry, representation of turbulent processes, and accounting for interactions between tides and sub-tidal processes (Lefevre et al., 2000). Even these models are frequently unsatisfactory, 
and further accuracy can only be obtained by assimilation of coastal tide gauge data where they are available. This is the approach taken by the U.S. Navy in their efforts to produce the most accurate high resolution coastal tide models (Blain et al., 2002), and it results in tidal fields which only approximately satisfy the relevant hydrodynamics models but which are in much better agreement with coastal tide data (Bennett, 1992; Egbert, 1997).

Obviously, data-assimilative tidal models require data to assimilate. The IHO "tidal data bank" is the largest single compendium of coastal tide station data, and it has been used by the U.S. Navy for the purpose of calibration and validation of tide models. However, assimilating this data into hydrodynamic models has yielded poor results (Zaron, personal communication, 2010), presumably due to lack of quality control of the original data, or lack of screening procedures to separate valid vs. spurious data for assimilation. For example, procedures which simply assimilate all IHO data within a computational domain often incorporate data from small rivers or estuaries where tidal dynamics cannot be accurately reproduced at the given model resolution. Hence, a large part of this project has involved categorizing station sites and defining quantitative metrics to guide the data selection process. The intercomparison of IHO data with matching GLOSS stations and OTIS tidal predictions has sought to develop criteria which could be used as the basis for objective selection procedures.

The Objectives of this study is on the following: 1). exploring the quality and 
accuracy of IHO data, and 2). examining the characteristics of stations with large error.

\subsection{Overview of tides}

Tides are periodical movements in the level of the surface of the sea or ocean, due to time dependent perturbations of gravity at the Earth's surface caused by the moon and sun (Doodson, 1941). Tides are important components of sea level variation and coastal current. The history of tides dates back to the time of ancient Greece. Philosophers tried to describe and explain tides based on their knowledge. Gradually, tides were linked to the motion of the sun and moon. Sir Issac Newton was the first person who conclusively explained equilibrium tide based on the theory of gravitational attraction of masses.

Several years after Newton's discovery, the French Academy offered a prize to the people who contributed to the theories of the tides. Daniel Bernoulli, Colin Maclaurin, Leonhard Euler and Antoine Cavalleri were these awarded scientists. Bernoulli developed the equilibrium theory sufficiently far to give it some practical value when predicting tides. Maclaurin verified for the first time that a homogeneous sphere would become a prolate ellopsoid when it is affected by the sun and moon (Harris, 1901). Euler concluded that tides are caused by the horizontal component of the moon's disturbing force. What's more, the famous French scientist Pierre Simon Laplace should be remembered the same as Newton for his contribution to tidal theories. He formulated the equations of motion, which can be used for tides on a rotating earth. He was the first person who consider tidal 
problems based on tidal species. However, he did not proceed to harmonic methods. The harmonic method of analysis and prediction was developed under Lord Kelvin's contribution. Some further development of harmonic methods were made by Sir George Darwin. (Doodson, 1941)

\subsubsection{Physics of tides}

Newton's law of gravitation states that any particle of mass $m_{1}$ attracts another particle of mass $m_{2}$ with a force which is proportional to the product of the two masses and the inverse of the square of their distance $r$ :

$$
\text { Force }=G \frac{m_{1} m_{2}}{r^{2}}
$$

where $\mathrm{G}$ is the universal gravitational constant whose value is approximately $6.67 \times$ $10^{-11} \mathrm{Nm}^{2} \mathrm{~kg}^{-2}$. Consider only the moon-earth system with the mass of the two bodies equivalently concentrated at their centers. 


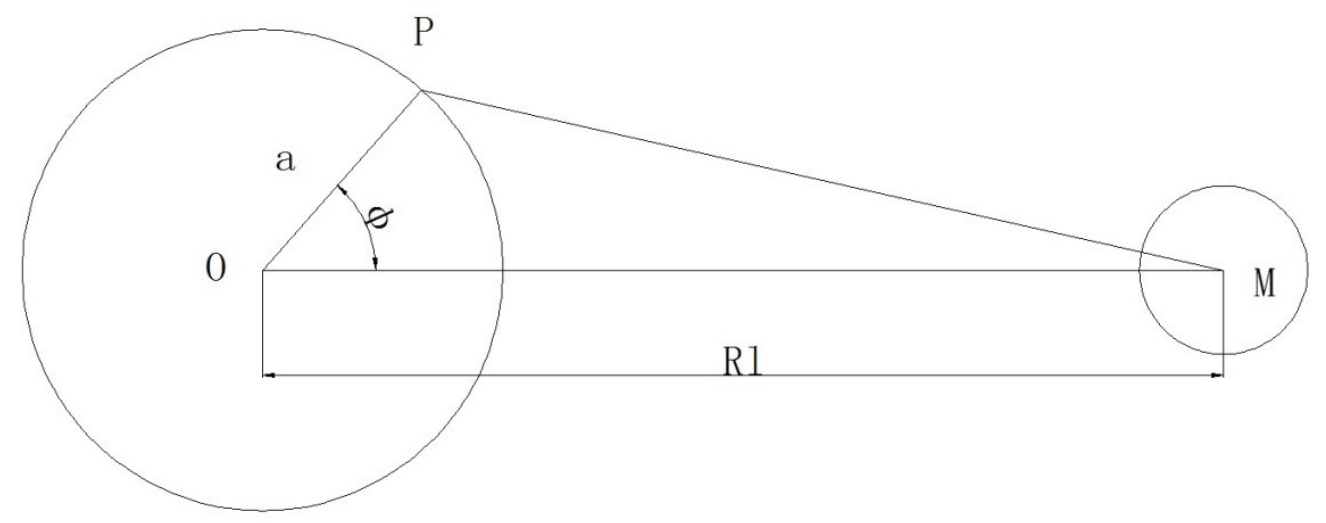

Figure 1. Diagram to show the location of the selected general point $\mathrm{P}$ on the earth surface.

The following arguments are about equilibrium tide only. The notations and processes are based on the derivation as described in Pugh (1987). The equilibrium theory of tides is a hypothesis under which it is assumed that the water covering the face of the earth instantly responds to the tide-producing forces of the moon and the sum and form a surface of equilibrium under the action of these forces (Schureman, 1976). It ignores friction, inertia and irregular affection of the land masses. Consider a particle of mass $\mathrm{m}$ located at $\mathrm{P}$ in figure 1 . The potential at $\mathrm{P}$ due to the moon is:

$$
\Omega_{\mathrm{P}}=-\frac{\mathrm{Gm}_{1}}{\overline{\mathrm{MP}}}
$$

Applying the cosine law to $\triangle \mathrm{OPM}: \overline{\mathrm{MP}}^{2}=\mathrm{a}^{2}+\mathrm{R}_{1}^{2}-2 \mathrm{aR}_{1} \cos \varphi$, then we have:

$$
\Omega_{\mathrm{p}}=-\frac{G \mathrm{~m}_{1}}{\mathrm{R}_{1}}\left\{1-2 \frac{\mathrm{a}}{\mathrm{R}_{1}} \cos \varphi+\frac{\mathrm{a}^{2}}{\mathrm{R}_{1}^{2}}\right\}^{-\frac{1}{2}}
$$

which can be expanded as a series of Legendre polynomials:

$$
\Omega_{\mathrm{p}}=-\frac{\mathrm{Gm}_{1}}{\mathrm{R}_{1}}\left[1+\frac{\mathrm{a}}{\mathrm{R}_{1}} \cos \varphi+\frac{\mathrm{a}^{2}}{\mathrm{R}_{1}^{2}} \times \frac{1}{2}\left(3 \cos ^{2} \varphi-1\right)\right.
$$




$$
\left.+\frac{\mathrm{a}^{3}}{\mathrm{R}_{1}^{3}} \times \frac{1}{2}\left(5 \cos ^{2} \varphi-3 \cos \varphi\right)+\cdots\right]
$$

On the right hand side of this equation, the first term is constant, so no force is produced. The second term produces a uniform force parallel to OM. The third term is the major term that producing tidal forces. All the higher order terms can be neglected because the radius of earth is small comparing to the distance between the moon and earth. Thus, the force that generates tides can be written as the following:

$$
\Omega_{\mathrm{p}}=-\frac{1}{2} \mathrm{Gm}_{1} \frac{\mathrm{a}^{2}}{\mathrm{R}_{1}^{3}}\left(3 \cos ^{2} \varphi-1\right)
$$

The lunar angle $\varphi$ can be expressed in other astronomical variables (Smart, 1940):

$$
\cos \varphi=\sin \varphi_{p} \sin d_{1}+\cos \varphi_{p} \cos d_{1} \cos C_{p}
$$

Substitute (5) to (4) with some rearrangement

$$
\begin{aligned}
-\Omega_{\mathrm{p}}= & \frac{3}{2} \operatorname{ag} \frac{\mathrm{m}_{1}}{\mathrm{~m}_{\mathrm{e}}}\left(\frac{\mathrm{a}}{\mathrm{R}_{1}}\right)^{3}\left[\frac{3}{2}\left(\sin ^{2} \mathrm{~d}_{1}-\frac{1}{3}\right)\left(\sin ^{2} \varphi_{\mathrm{p}}-\frac{1}{3}\right)\right. \\
& \left.+\frac{1}{2} \sin 2 \mathrm{~d}_{1} \sin 2 \varphi_{\mathrm{p}} \cos C_{\mathrm{p}}+\right]
\end{aligned}
$$

where $d_{1}$ is the lunar declination, which is equivalent to geocentric latitude, $\varphi_{p}$ is the geodetic latitude, $\mathrm{C}_{\mathrm{p}}$ is the angle between the meridian plane and the plane that containing the Earth's axis and $\mathrm{P}$ (hour angle of $\mathrm{P}$ ). This equation is used to compute equilibrium tide. 


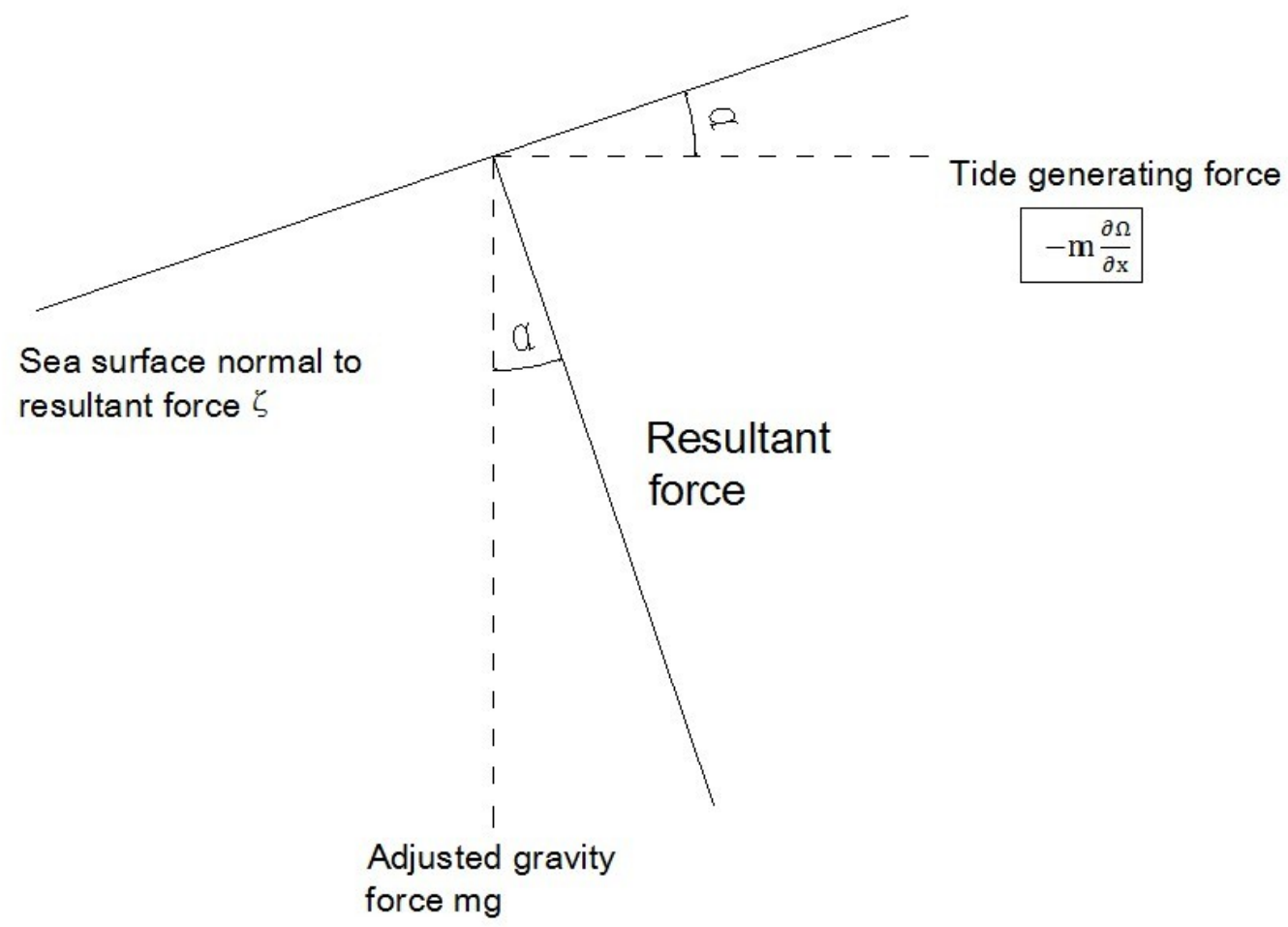

Figure 2. The relationship between the Equilibrium water surface, the tide generating force, and the normal

earth's gravity force.

If the tidal generating force, gravity of $\mathrm{P}$ and the equilibrium surface is as shown in

figure 2 , then

$$
\tan \alpha=-\frac{\left(\frac{\partial \Omega \mathrm{p}}{\partial \mathrm{x}}\right)}{\mathrm{g}}=\left(\frac{\partial \bar{\zeta}}{\partial \mathrm{x}}\right)
$$

So that

$$
\frac{\partial}{\partial \mathrm{x}}\left(\mathrm{g} \bar{\zeta}+\Omega_{\mathrm{p}}\right)=0,
$$

and similarly in the y direction,

$$
\frac{\partial}{\partial y}\left(g \bar{\zeta}+\Omega_{p}\right)=0 .
$$


Integrate over a finite area, if the total volume of water is conserved, then

$$
\mathrm{g} \bar{\zeta}+\Omega_{\mathrm{p}}=0
$$

and substitute the tidal potential back, we get:

$$
\bar{\zeta}=a\left(\frac{m_{1}}{m_{e}}\right)\left[C_{0}(t)\left(\frac{3}{2} \sin ^{2} \varphi_{p}-\frac{1}{2}\right)+C_{1}(t) \sin 2 \varphi_{p}+C_{2}(t) \cos ^{2} \varphi_{p}\right]
$$

where the coefficients are:

$$
\begin{aligned}
& \mathrm{C}_{0}(\mathrm{t})=\left(\frac{\mathrm{a}}{\mathrm{R}_{1}}\right)^{3}\left(\frac{3}{2} \sin ^{2} \mathrm{~d}_{1}-\frac{1}{2}\right) \\
& \mathrm{C}_{1}(\mathrm{t})=\left(\frac{\mathrm{a}}{\mathrm{R}_{1}}\right)^{3}\left(\frac{3}{4} \sin ^{2} 2 \mathrm{~d}_{1} \cos \mathrm{C}_{\mathrm{p}}\right) \\
& \mathrm{C}_{2}(\mathrm{t})=\left(\frac{\mathrm{a}}{\mathrm{R}_{1}}\right)^{3}\left(\frac{3}{4} \cos ^{2} 2 \mathrm{~d}_{1} \cos 2 \mathrm{C}_{\mathrm{p}}\right)
\end{aligned}
$$

These three coefficients represents the three main species of tides: the long period species, the diurnal species and the semidiurnal species.

\subsubsection{Tidal Species}

Tides are divided into species with different periods. Diurnal tides are those with a period of about a day. Semidiurnal tides are those with a period of about half a day.

Terdiurnal tides have a period of about one third a day. Quarterdiurnal tides have a period of about on fourth a day and so on. The long period species are those with periods from 14 days to 19 years.

\subsubsection{Classical Tidal Analysis and Tidal Constituents}

Harmonic analysis is a basic method widely used for tidal analysis. It treats tides as a 
sum of a finite number of harmonic constituents whose angular speeds (frequencies) and phases have been predetermined. The harmonics can be expressed in the forms as following:

$$
H_{n} \cos \left(\sigma_{n} t+g_{n}\right)
$$

where $H_{n}$ is an amplitude, $\sigma_{n}$ is angular speed in degrees per mean solar hour, $g_{n}$ is a phase lag on the equilibrium tide.

The angular speed $\omega_{\mathrm{n}}\left(\omega_{\mathrm{n}}=\sigma_{\mathrm{n}} \times \frac{2 \pi}{3600}\right.$ if $\omega_{\mathrm{n}}$ in radian/sec $)$ can be determined as a expansion of a sum of equilibrium tidal harmonic terms:

$$
\omega_{\mathrm{n}}=\mathrm{i}_{\mathrm{a}} \omega_{1}+\mathrm{i}_{\mathrm{b}} \omega_{2}+\mathrm{i}_{\mathrm{c}} \omega_{3}+\mathrm{i}_{\mathrm{d}} \omega_{4}+\mathrm{i}_{\mathrm{e}} \omega_{5}+\mathrm{i}_{\mathrm{f}} \omega_{6}
$$

where the values of $\omega$ are the angular speeds predefined in table 1 , the coefficients $i_{a}$ to $i_{f}$ are small integers.

Consider first a term in the form of:

$$
Y\left(1+\alpha \cos \omega_{x} t\right) \cos \omega_{y} t
$$

which can be rearranged using the basic rules of trigonometry for combining sine and cosine terms:

$$
\mathrm{Y}\left[\cos \omega_{\mathrm{y}} \mathrm{t}+\frac{\alpha}{2} \cos \left(\omega_{\mathrm{x}}+\omega_{\mathrm{y}}\right) \mathrm{t}+\frac{\alpha}{2} \cos \left(\omega_{\mathrm{y}}-\omega_{\mathrm{x}}\right) \mathrm{t}\right]
$$

The harmonic modulation in the amplitude of a constituent of speed $\omega_{\mathrm{y}}$ is represented by two additional harmonic terms with speed $\left(\omega_{\mathrm{x}}+\omega_{\mathrm{y}}\right)$ and $\left(\omega_{\mathrm{y}}-\omega_{\mathrm{x}}\right)$. Consider first the semidiurnal part of the equilibrium tide in equation (12) (13) (14), the lunar distance $R_{1}$ is from the equation (Roy, 1978): 


$$
\frac{\overline{\mathrm{R}_{1}}}{\mathrm{R}_{1}}=(1+\mathrm{e} \cos (\mathrm{s}-\mathrm{p})+\text { solar perturbations })
$$

where $\overline{\mathrm{R}_{1}}$ is the mean lunar distance, $\mathrm{s}$ is the moon's geocentric mean ecliptic longitude which increases by $0.5490^{\circ}$ per mean solar hour, $p$ is the longitude of lunar perigee, which rotates with an 8.85-year period, e is the eccentricity of the ellipse. Then we get

$$
\mathrm{C}_{2}(\mathrm{t})=\left[\left(\frac{\mathrm{a}}{\mathrm{R}_{1}}\right)^{3} \frac{3}{4} \cos ^{2} \mathrm{~d}_{1}\right][1+\mathrm{e} \cos (\mathrm{s}-\mathrm{p})]^{3} \cos 2 \mathrm{C}_{1}
$$

For convenience, $\left[\left(\frac{\mathrm{a}}{\mathrm{R}_{1}}\right)^{3} \frac{3}{4} \cos ^{2} \mathrm{~d}_{1}\right]$ is simplified as $\mathrm{Y}$.

Another approximation is made as:

$$
[1+e \cos (s-p)]^{3} \approx 1+3 e \cos (s-p)
$$

where terms in $\mathrm{O}\left(\mathrm{e}^{2}\right)$ and above are neglected.

For lunar hour angle $\mathrm{C}_{1}$,

$$
C_{1}=\lambda_{p}+\left(\omega_{0}+\omega_{3}\right) t-\pi-A_{1}
$$

where let $A_{1} \approx \lambda_{1}$ (Roy, 1978)

$$
\lambda_{1}=s+2 e \sin (s-p)+\text { solar perturbations }
$$

we have

$$
\cos 2 \mathrm{C}_{1}=\cos 2\left[\omega_{0} \mathrm{t}+\mathrm{h}-\mathrm{s}-\pi-2 \mathrm{e} \sin (\mathrm{s}-\mathrm{p})\right]
$$

Write $\delta=\omega_{0} t+h-s-\pi$ to simplify:

$$
\begin{aligned}
\cos 2 \mathrm{C}_{1} & =\cos 2 \delta \cos [2 \mathrm{e} \sin (\mathrm{s}-\mathrm{p})]+\sin 2 \delta \sin [2 \mathrm{e} \sin (\mathrm{s}-\mathrm{p})] \\
& \approx \cos 2 \delta+2 \mathrm{e} \sin (\mathrm{s}-\mathrm{p}) \sin 2 \delta
\end{aligned}
$$

Substitute this back to $(20)$ and neglecte $\mathrm{O}\left(\mathrm{e}^{2}\right)$ terms:

$$
\mathrm{C}_{2}(\mathrm{t})=\mathrm{Y}[\cos 2 \delta+4 \mathrm{e} \sin (\mathrm{s}-\mathrm{p}) \sin 2 \delta+3 \mathrm{e} \cos (\mathrm{s}-\mathrm{p}) \cos 2 \delta]
$$




$$
\begin{aligned}
& =\mathrm{Y}\left[\cos 2 \delta+\frac{4}{2} \mathrm{e} \cos (2 \delta-\mathrm{s}+\mathrm{p})-\frac{4}{2} \mathrm{e} \cos (2 \delta+\mathrm{s}-\mathrm{p})+\right. \\
& \left.\quad \frac{3}{2} \mathrm{e} \cos (2 \delta+\mathrm{s}-\mathrm{p})-\frac{3}{2} \mathrm{e} \cos (2 \delta-\mathrm{s}+\mathrm{p})\right] \\
& =\mathrm{Y}\left[\cos 2 \delta+\frac{7}{2} \mathrm{e} \cos (2 \delta-\mathrm{s}+\mathrm{p})-\frac{1}{2} \mathrm{e} \cos (2 \delta-\mathrm{s}+\mathrm{p})\right]
\end{aligned}
$$

Then replace $\delta$ :

$$
\begin{aligned}
C_{2}(t)= & Y\left[\cos \left(2 \omega_{0} t+2 h-2 s\right)+\frac{7}{2} e \cos \left(2 \omega_{0} t+2 h-3 s+p\right)+\right. \\
& \left.\frac{1}{2} e \cos \left(2 \omega_{0} t+2 h-s-p+180^{\circ}\right)\right]
\end{aligned}
$$

The first term of the above equation is the main semidiurnal lunar tide M2, where the letter $\mathrm{M}$ represent the moon, 2 represent semidiurnal tide. The lunar and solar mean longitudes $s$ and $h$ increases at rates $\omega_{2}$ and $\omega_{3}$, which gives $2\left(\omega_{0}-\omega_{2}+\omega_{3}\right)$ as the speed of M2. The second and third terms in (27) are N2 and L2 respectively. The amplitudes are not equal. According to (27) the relative amplitudes are:

$$
\text { N2: M2: L2 = 0.196: 1.000: 0.027 }
$$

Equation (27) for $\mathrm{C}_{2}(\mathrm{t})$ is simplified. The full expansion of $\mathrm{C}_{2}(\mathrm{t})$ must include the effects of the obliquity on the right ascension (the angular distance eastward along the celestial equator from the vernal equinox to the hour circle of the point), the effects of the declination $\cos ^{2} \mathrm{~d}_{1}$ and the approximation for orbit parameters. As a result, the number of harmonic constituents is large. However, only a limited number of harmonics are dominant. The relative amplitude is given in table 2 and table 3.

The full set of $i_{a}$ to $i_{f}$ defines a harmonic. Doodson (1921) defines species in terms of lunar speed. For example, he coded the constituent M2 as (2 00000 ). Detailed 
Doodson numbers are also tabulated in tables 2 and table 3.

Table 1. Basic periods and frequencies of astronomical motions.

\begin{tabular}{|c|c|c|c|c|}
\hline & & \multicolumn{2}{|c|}{ Frequency } & \multirow{4}{*}{$\begin{array}{c}\text { Angular speed } \\
\text { Symbol in radians }\end{array}$} \\
\hline & & $\mathrm{f}$ & $\sigma$ & \\
\hline & & (cycles per mean & (degrees per mean & \\
\hline & & solar day) & solar hour) & \\
\hline Mean solar day & $1.00 \mathrm{MSD}^{*}$ & 1.00 & 15.0 & $\omega_{0}$ \\
\hline Mean lunar day & 1.0351MSD & 0.9661369 & 14.4921 & $\omega_{1}$ \\
\hline Sidereal month & 27.3217MSD & 0.0366009 & 0.5490 & $\omega_{2}$ \\
\hline Tropical year & 365.2422MSD & 0.0027379 & 0.0411 & $\omega_{3}$ \\
\hline Moon's perigee & $8.85 \mathrm{JY}^{* *}$ & 0.00030937 & 0.0046 & $\omega_{4}$ \\
\hline Regression of & $18.61 \mathrm{JY}$ & 0.0001471 & 0.0022 & $\omega_{5}$ \\
\hline \multicolumn{5}{|l|}{ moon's nodes } \\
\hline Perihelion & 20942JY & - & - & $\omega_{6}$ \\
\hline
\end{tabular}

$* \mathrm{MSD}=$ mean solar days; $* * \mathrm{JY}=\mathrm{Julian}$ years. 
Table 2. Astronomical diurnal tides; $\mathrm{i}_{\mathrm{a}}=1$.

\begin{tabular}{|c|c|c|c|c|c|c|c|c|c|c|}
\hline & \multirow[b]{2}{*}{$\mathrm{i}_{\mathrm{b}}$} & \multicolumn{3}{|c|}{ Argument } & \multirow[b]{2}{*}{$i_{f}$} & \multirow{2}{*}{$\begin{array}{l}\text { Period } \\
\text { (msd) }\end{array}$} & \multicolumn{2}{|c|}{ Speed } & \multirow{2}{*}{$\begin{array}{l}\text { Relative } \\
\text { coefficient } \\
(\mathrm{M} 2=1.0000)\end{array}$} & \multirow[t]{2}{*}{ Origin } \\
\hline & & $\mathrm{i}_{\mathrm{c}}$ & $\mathrm{i}_{\mathrm{d}}$ & & & & $\mathrm{f}(\mathrm{cpd})$ & $\sigma\left({ }^{\circ} / \mathrm{h}\right)$ & & \\
\hline $\mathrm{O} 1$ & -1 & 0 & 0 & 0 & 0 & 1.076 & 0.9295 & 13.9430 & 0.4151 & Principal lunar \\
\hline $\mathrm{P} 1$ & 1 & -2 & 0 & 0 & 0 & 1.003 & 0.9973 & 14.9589 & 0.1932 & Principal solar \\
\hline $\mathrm{S} 1$ & 1 & -1 & 0 & 0 & 0 & 1.000 & 1.0000 & 15.0000 & - & Radiational \\
\hline K1 & 1 & 1 & 0 & 0 & 0 & 0.997 & 1.0027 & 15.0411 & 0.3990 & Principal lunar \\
\hline & 1 & 0 & 0 & 0 & 0 & 0.997 & 1.0027 & 15.0411 & 0.1852 & Principal solar \\
\hline $\mathrm{J} 1$ & 2 & 0 & -1 & 0 & 0 & 0.962 & 1.0390 & 15.5854 & 0.0326 & Elliptical lunar \\
\hline
\end{tabular}


Table 3. Astronomical semidiurnal tides; $\mathrm{i}_{\mathrm{a}}=2$.

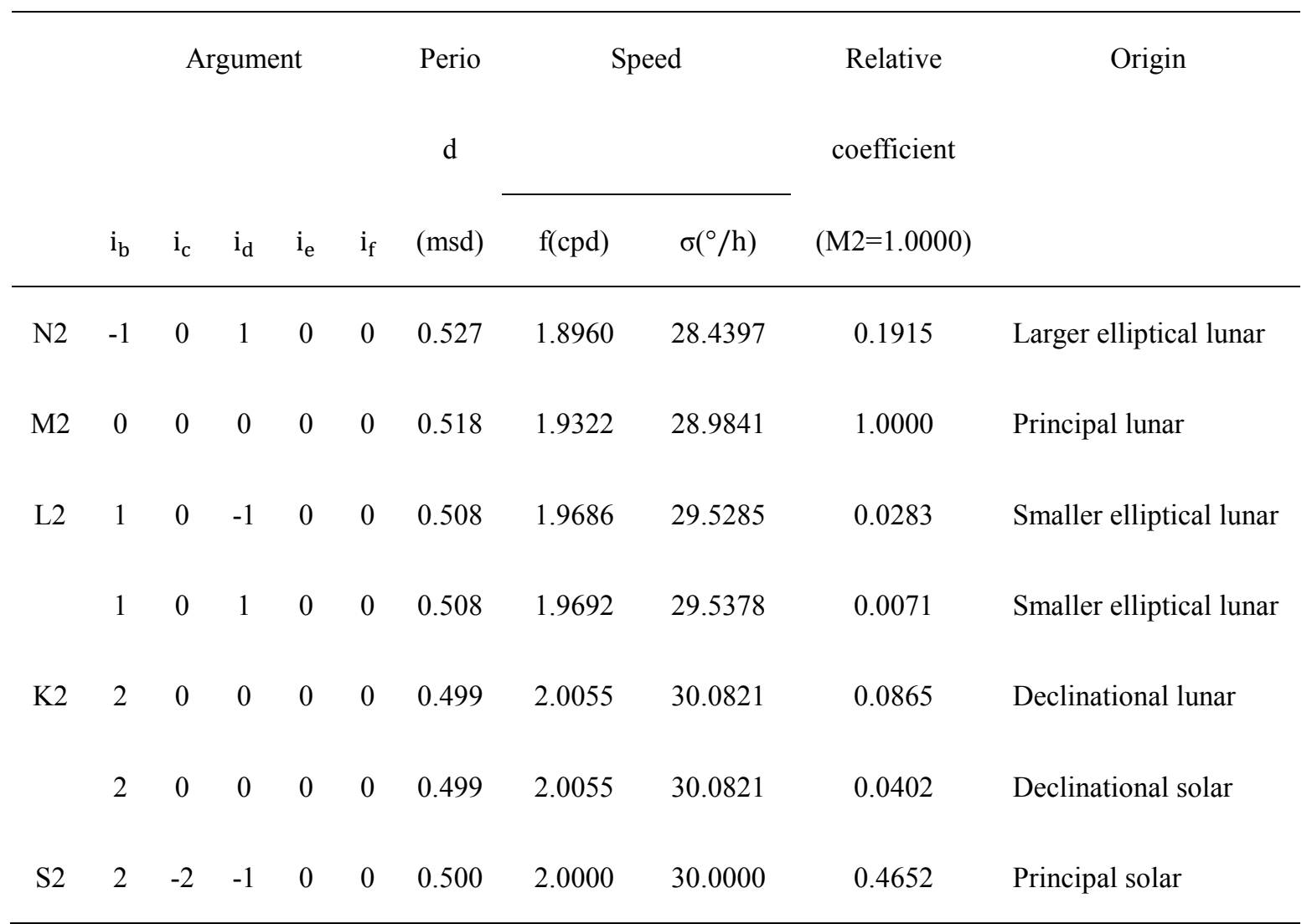

\subsection{Issues}

The IHO tidal constituents data bank consists of harmonic constants for sea level over 4000 tide gauge stations. Most stations are in coastal areas.

One drawback of using IHO data is most tide gauges distribute in coastal areas that are affected by rivers, manmade constructions, complex topographic features, etc. The astronomically-forced tidal constituents may be influenced by river flow or other signals.

The other drawback of using IHO data is its unknown precision. Although we know 
that all the harmonic constants are computed from time series of sea surface height (SSH) data, no time series is available in the IHO data bank. The precision of longitude and latitude coordinates of the location of each tide gauge is also problematic. The three decimal digits precision of longitude and latitude can lead to uncertainty in georeferencing of approximately $1000 \mathrm{~m}$ at the equator. For example, when viewing the actual location of one tide gauge in Google Earth, it is sometimes hard to distinguish which surrounding geomorphologic feature dominates this tide gauge according to the vicinity of it.

\subsection{Hypothesis}

Three hypothesis were made and tested: 1 . the complexity of the surrounding coastline of a station is proportional to the length of the narrowest path from the station to the open ocean. The differences between IHO data and tidal model output were expected to be inversely proportional to the defined length scale; 2 . the morphological features of each station location in IHO can be described by using non-exclusive categories; 3 . the precision of each constituent in IHO could be related to the smallest amplitude of the constituent in each tidal species. 


\section{Chapter 2: Data and Method}

\subsection{Data Sources}

The International Hydrographic Organization (IHO) tidal data is the primary data used in this study. Besides IHO tidal data, the Global Sea Level Observing System (GLOSS) data, O.S.U. Tidal Inversion Software (OTIS) model output and some other data are also used.

The data in the original IHO database were contributed by member states of the International Hydrographic Organization. However, since approximately the year 2000, at the request of member states, the IHO has stopped distributing these data (Ray, personal communication, 2011). Presently, several versions of the database exist (Ray, personal communication). The version utilized here was provided by Scott Smith at the Naval Research Lab (NRL) and it is presumed to be identical to the version in the PC Tides software (Posey et al., 2008). The version of IHO data used in this study consists of 4131 tide gauge stations, which distribute all around the globe. The longitude, latitude, and time zone of each stations are given. The precision of location coordinate is 3 decimal digits. Each station has a number of constituents no less than 4 . For each tidal constituent, available information includes amplitude, phase in both local and Greenwich time zone, and frequency. Note that the time series of SSH data of each tide gauge are not in the original data base. The IHO stations are distributed as shown in figure 3 . 


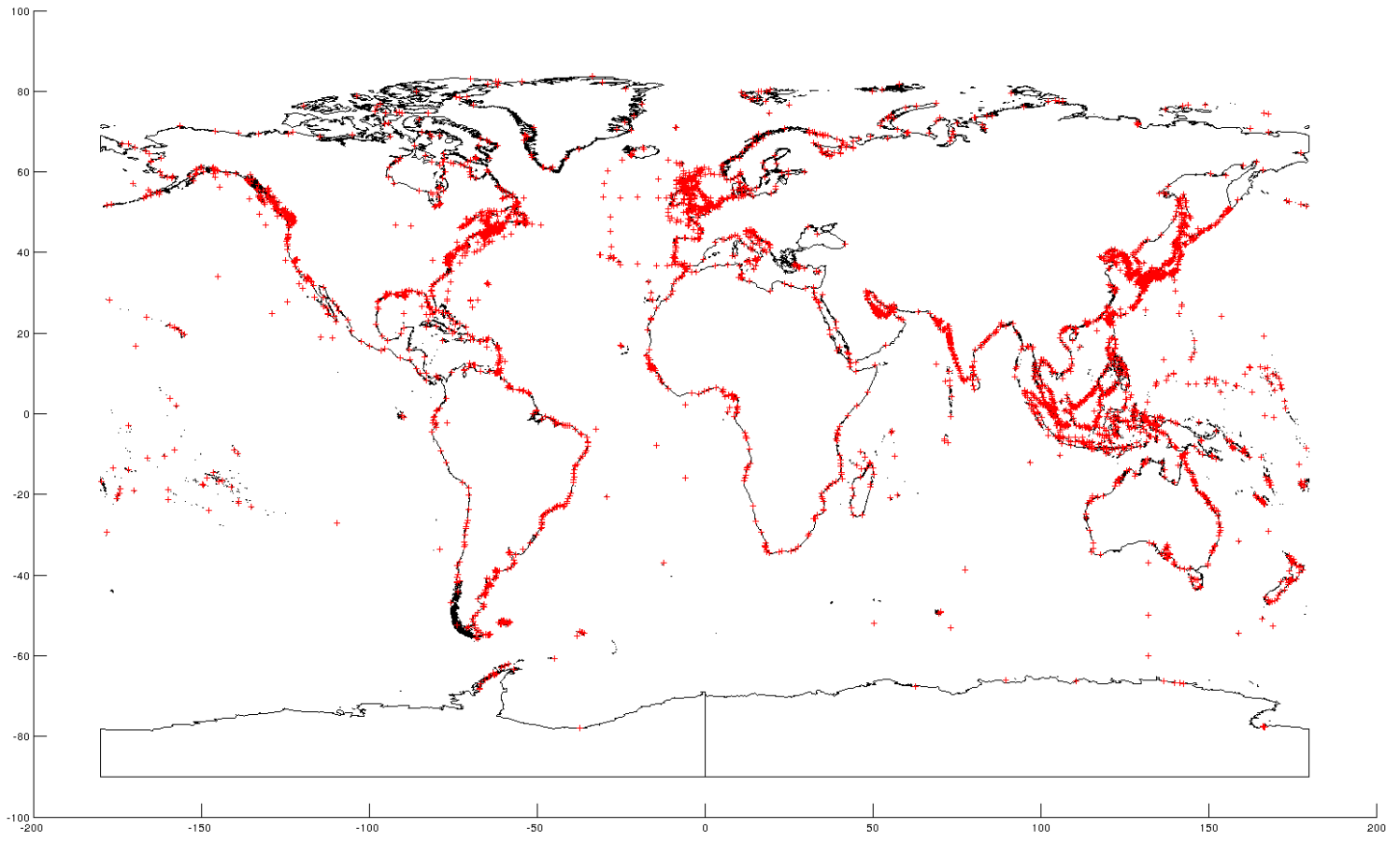

Figure 3. IHO station distribution.

Because of the unknown precision and complex surrounding topography of IHO data, GLOSS data is used in this study to help compare and decide the reliability of IHO data (Merrifield et al., 2009). GLOSS was established in 1985. It is an international program conducted under the auspices of the Joint Technical Commission for Oceanography and Marine Meteorology (JCOMM) of the World Meteorological Organization (WMO) and the Intergovernmental Oceanographic Commission (IOC) (Merrifield et al., 2009).

GLOSS establishes high quality global and regional sea level networks for application to climate, oceanographic and coastal sea level research. The GLOSS sea level data bank consists about 300 sea level stations around the world with high quality, long term sea level data. In this study, a total number of 256 research quality sea level records are 
downloaded from University of Hawaii Sea Level Center database. The locations of these tide stations are shown in figure 4.

Among 256 downloaded GLOSS tidal stations, some locate close to those in IHO data base. As a result, these stations are selected as duplicate stations for comparison. A station is defined as a duplicate station when the station exists in both IHO and GLOSS database, and the distance between the two coordinates in two database is smaller than $10 \mathrm{~km}$. An example of a duplicate station, 'Cascais', is shown in figure 5, where the yellow pin is the staion in IHO database, and the red pin is the station in GLOSS database.

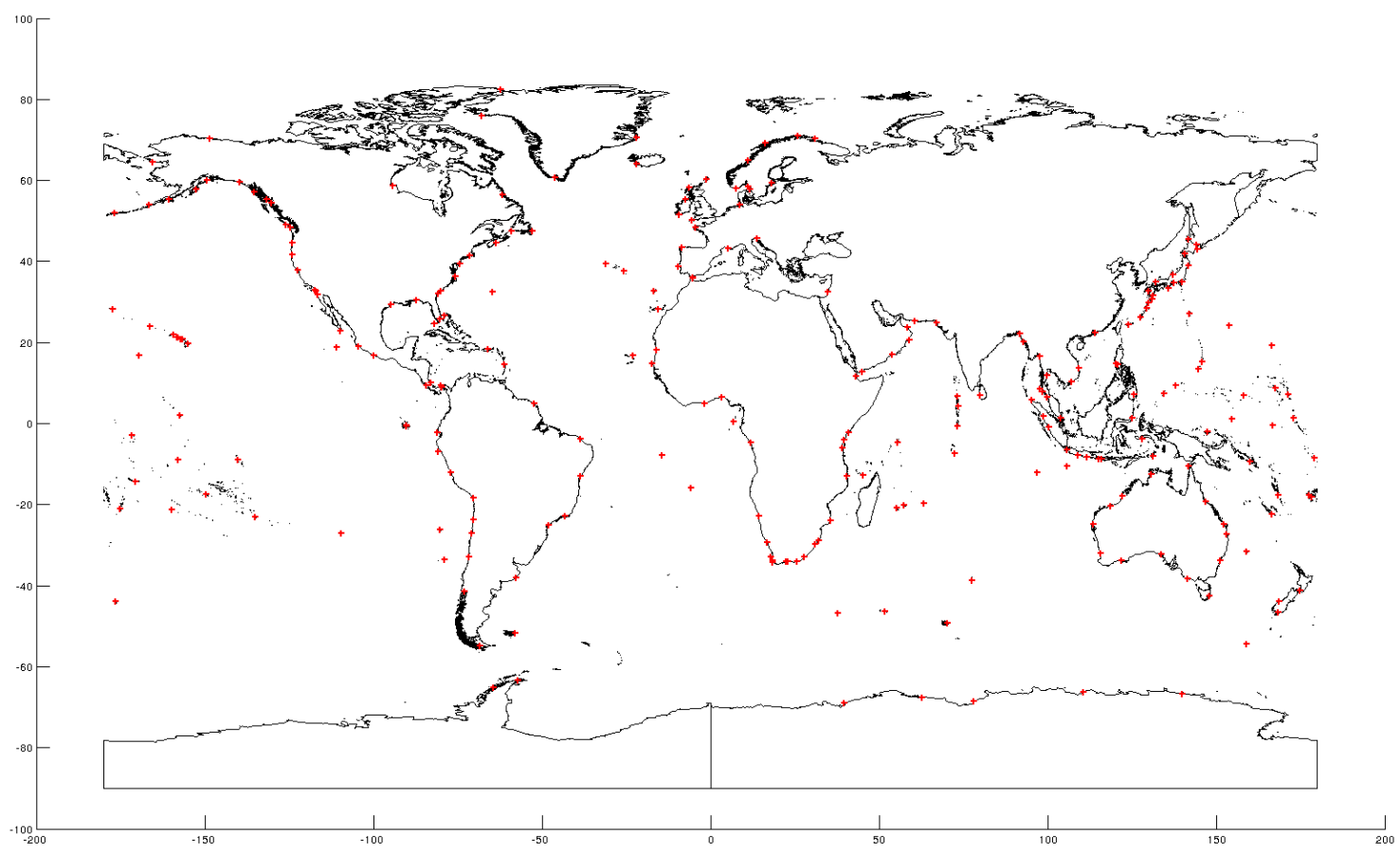

Figure 4. GLOSS tide gauge distribution. 


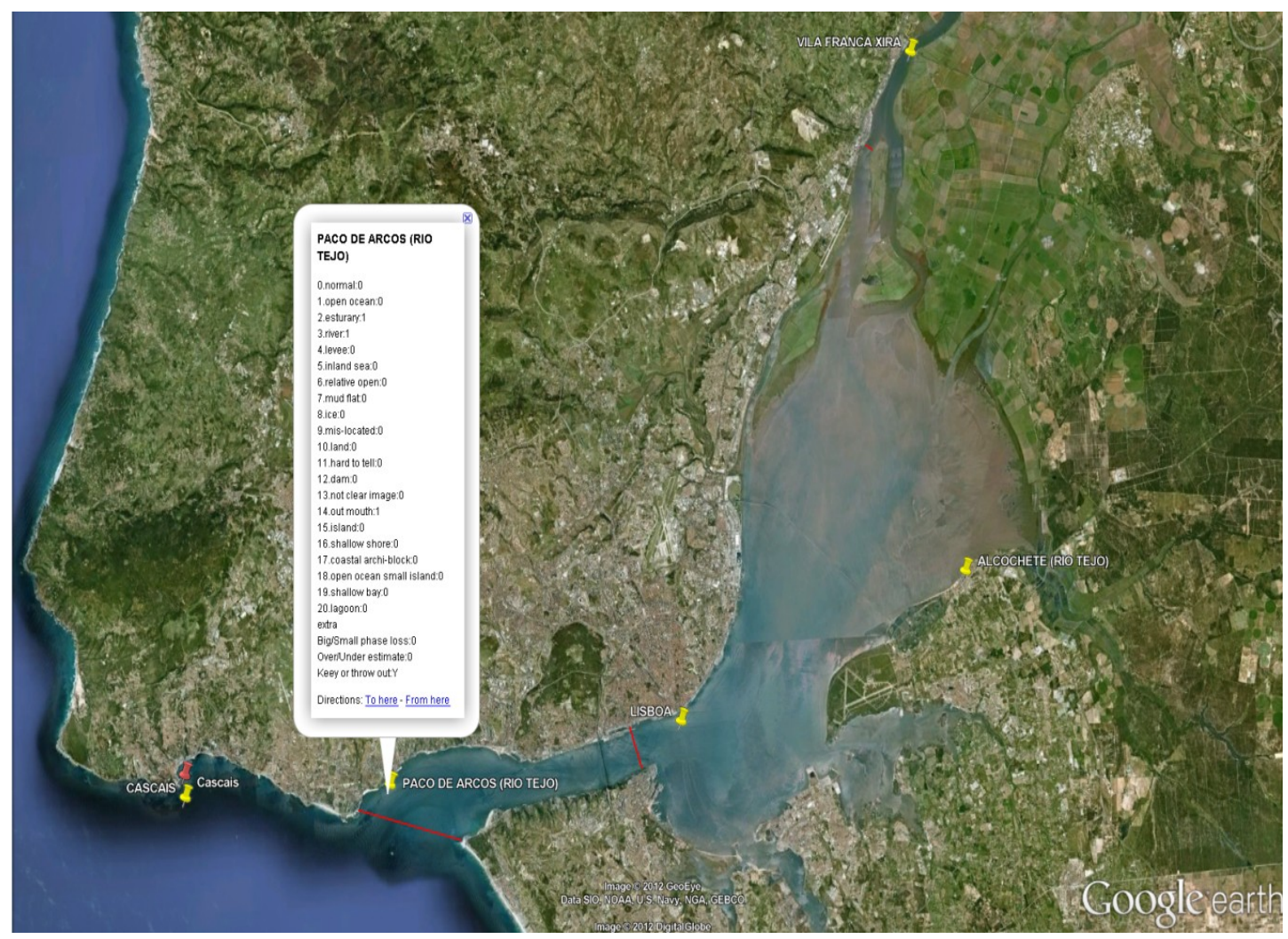

Figure 5. A typical river-estuary-mouth station distribution in Tagus River, Portugal. Red segments are

defined characteristic length scale. Yellow pins are IHO stations, red pins are GLOSS stations.

To test the usability of IHO data bank in numerical modeling, the outputs of O.S.U.

Tidal Inversion Software (OTIS) are used for comparison. TPXO7.2 is the current version of a global model of ocean tides, which best fits, in a least square sense, the Laplace Tidal Equations and data from TOPEX/Poseidon and Jason satellite altimeters (Egbert \& Erofeeva, 2002). The global results of TPXO7.2 are the amplitude of eight primary (M2, S2, N2, K2, K1, O1, P1, Q1), two long-period (Mf, Mm), and 3 non-linear (M4, MS4, MN4) harmonic constituents at 1/4 degree resolution.

In OTIS, the generalized inversion scheme of Egbert et al. (1994) is used. The tidal 
fields $\mathbf{u}$ are consistent both with the hydrodynamic equations

$$
\mathbf{S u}=\mathbf{f}_{0},
$$

and with a K-dimensional vector $\mathrm{d}$ of tidal data

$$
\mathbf{d}=\mathbf{L u}
$$

The differential operator $\mathrm{S}$ is given by

$$
\mathrm{S}=\left[\begin{array}{cc}
\mathbf{F} & \mathrm{gHG} * \nabla \\
\nabla & \mathrm{i} \omega
\end{array}\right] \quad \mathbf{F}=\left[\begin{array}{cc}
\mathrm{i} \omega+\mathrm{k} & -\mathrm{f} \\
\mathrm{f} & \mathrm{i} \omega+\mathrm{k}
\end{array}\right]
$$

where $\mathrm{H}$ is the ocean depth, $\mathrm{f}$ is the Coriolis acceleration, $\omega$ is the constituent frequency,

$\nabla$ and $\nabla \cdot$ represent the two-dimensional gradient and divergence operators on the spherical Earth, and $\mathrm{k}$ represents dissipation, $\mathrm{G} *$ represents convolution with the Green's function for tidal loading and ocean self-attraction (Hendershott, 1972). By minimizing the quadratic penalty function

$$
\mathrm{J}[\mathbf{d}, \mathbf{u}]=(\mathbf{L u}-\mathbf{d})^{*} \sum_{\mathrm{e}}^{-1}(\mathbf{L u}-\mathbf{d})+\left(\mathbf{S u}-\mathbf{f}_{0}\right)^{*} \sum_{\mathrm{f}}^{-1}\left(\mathbf{S u}-\mathbf{f}_{0}\right)
$$

the tidal fields which are in approximate agreement with observations which also approximately satisfy the Laplace Tidal Equations can be computed. Here $\sum_{\mathrm{e}}$ and $\sum_{\mathrm{f}}$ are the covariances for the data and dynamical errors, and the asterisk denotes the complex conjugate transpose.

Amplitudes and phases of four major tidal constituents M2, S2, K1 and O1 are extracted at IHO tide gauge locations using Tidal Model Driver (TMD). TMD is a Matlab package for accessing the harmonic constituents for the ESR/OSU family of high-latitude tide models, and for making predictions of tide height and currents (Padman, 2005). The 
M2 amplitude solution is shown in figure 6. In some IHO station locations, the model output does not have a valid value due to the coarse resolution of bathymetry grid in OTIS. These stations are excluded in comparisons.

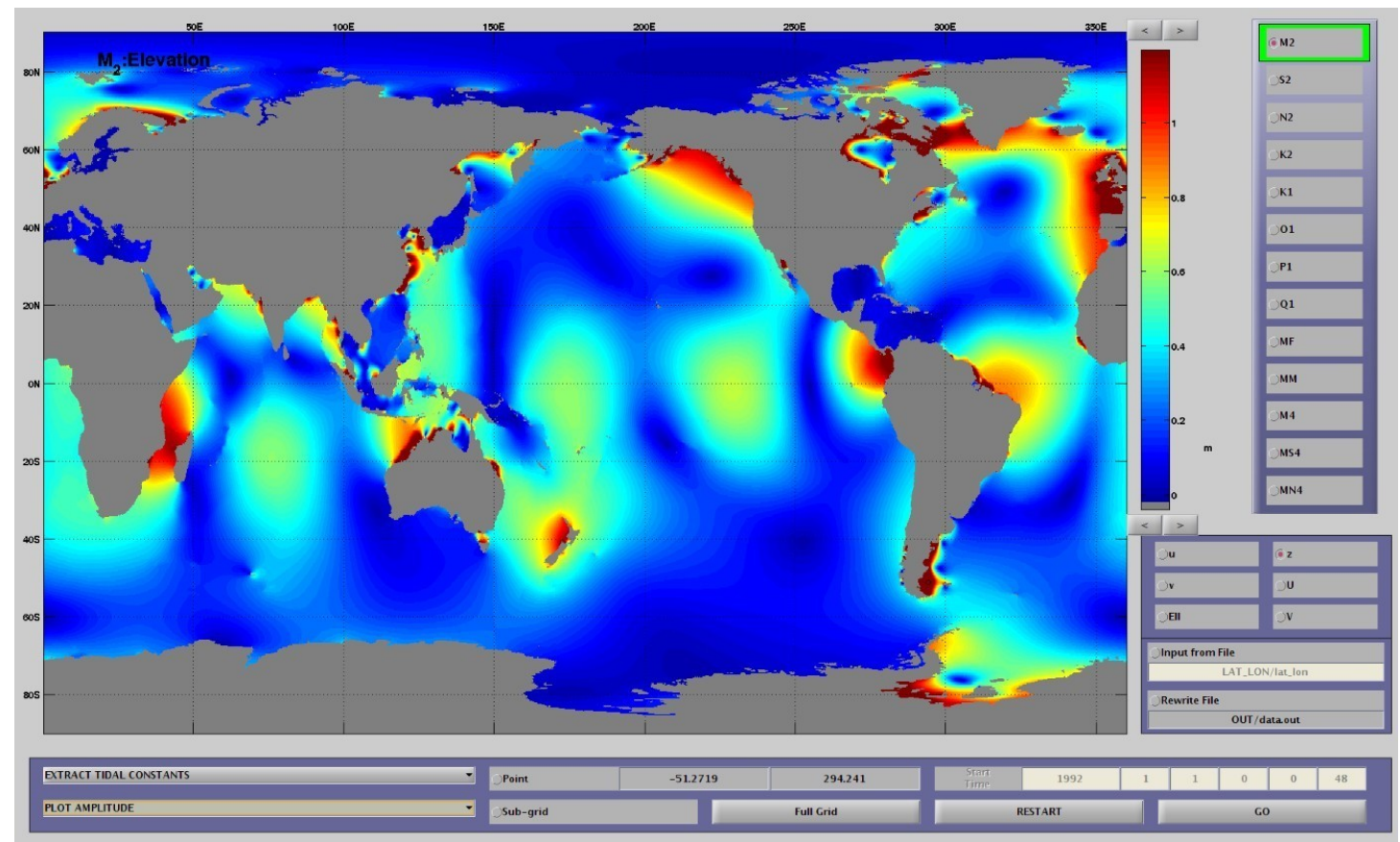

Figure 6. TPXO7.2 M2 amplitude solution.

The General Bathymetric Chart of the Oceans (GEBCO) data is used. The resolution is 1 minute all around the globe. The data is then imported in to a Matlab GUI and used as a base to compute the distance to a certain iso-level.

The Global Self-consistent, Hierarchical, High-resolution (200m resolution) Shoreline Database (GSHHS) (Wessel \& Smith, 1996) is extracted and plotted by m_map (a matlab tool box for mapping) to conduct detailed comparisons with 1/4 minute resolution grid in OTIS for stations along the coastline. 


\subsection{Quality Control in Google Earth}

Due to the complicated topographic features around most IHO tide gauge stations and the uncertainty of IHO data itself, quality control is needed to classify stations. Google Earth provides an efficient and precise way of visualizing and hand editing the data, and is used in this study. Google Earth is a virtual globe, map and geographical information program. It maps the earth by the superimposition of images obtained from satellite imagery, aerial photography and a GIS 3D globe (Bazilchuk, 2006). It has a resolution of $30 \mathrm{~m}$ or finer in continental areas, and $500 \mathrm{~m}$ or finer in the open oceans which is much finer than other available coastline configuration and bathymetry data.

Two important features are defined for each station by manually looking at the georeferenced imagery around each station: a characteristic length scale of each tide station was defined to judge whether the tide gauge is resolvable by comparing its characteristic length scale with model resolution; and categorization is made to describe the complex morphologic feature of each station. An example is shown in figure 5. Defined characteristic length scales are shown as red segments. Categories are tabulated for each station. A detailed list of categories is shown in table 4 .

Table 4. 21 non-exclusive categories.

\begin{tabular}{|l|l|}
\hline \multicolumn{2}{|c|}{21 Categories defined for IHO stations } \\
\hline 1. Normal & the scale segments of stations are determined by their own topographic \\
\hline
\end{tabular}




\begin{tabular}{|c|c|}
\hline & feature \\
\hline 2. Open ocean & station located in relative open ocean or with scale larger than $15 \mathrm{~km}$ \\
\hline 3. Estuary & $\begin{array}{l}\text { stations located in transition zone of a river, they may be affected by } \\
\text { either or both river flow and tidal flow }\end{array}$ \\
\hline 4. River & stations which are affected by river flow \\
\hline 5. Levee & stations which are affected by artificial or natural formed structures \\
\hline 6. Inland sea & Persian Gulf, Red Sea, Mediterranean, Black Sea \\
\hline 7. Relative open & stations which are located in an archipelago-like area \\
\hline 8. Mud flat & $\begin{array}{l}\text { stations located on a mud flat (this may be caused by false image from } \\
\text { Google Earth or seasonal variation of water) }\end{array}$ \\
\hline 9. Ice & stations surrounded by ice (only visually identified) \\
\hline 10. Mis-located & $\begin{array}{l}\text { if two or more station names are associated with the same coordinate, } \\
\text { these stations are marked as this category }\end{array}$ \\
\hline 11. Land & stations located far inland and far from a river \\
\hline 12. Hard to tell & $\begin{array}{l}\text { stations located in a location with two or more possible characteristic } \\
\text { length scale choices }\end{array}$ \\
\hline 13. Dam & stations located upstream of a dam-like structure \\
\hline 14. Not clear image & $\begin{array}{l}\text { no clear image is available from Google Earth, this may happen when } \\
\text { the image is blocked by cloud }\end{array}$ \\
\hline
\end{tabular}




\begin{tabular}{|c|c|}
\hline 15. Out mouth & $\begin{array}{l}\text { stations located outside but near the mouth of a river, they may still be } \\
\text { affected by river flow }\end{array}$ \\
\hline 16. Island & stations located on atolls \\
\hline 17. Shallow shore & stations located in an area with a shallow shelf \\
\hline 18. Coastal archi-block & $\begin{array}{l}\text { stations located close to a coastline with archipelago-like island blocking } \\
\text { outside }\end{array}$ \\
\hline $\begin{array}{l}\text { 19. Open ocean small } \\
\text { island }\end{array}$ & $\begin{array}{l}\text { if the travel time of tidal waves from the open ocean to the station is } \\
\text { short and if the stations locate in an island, these stations are marked as } \\
\text { this category }\end{array}$ \\
\hline 20. Shallow bay & $\begin{array}{l}\text { stations which are located in a bay with ratio of major radius to short } \\
\text { radius larger than 1:0.5. Some small bays are also included }\end{array}$ \\
\hline 21. Lagoon & stations which are located in a lagoon \\
\hline
\end{tabular}

A line segment for each station is defined by the width of the narrowest path from the station to the open ocean. It is dependent on the vicinity area of each station. The two end points of the segment are defined in Google Earth and then the length of the segment is computed using the Bowring formula (Bowring, 1983) for an ellipsoidal earth.

\subsection{Distances to isobaths}

Distances to shoreline, distances to 50 meter depth iso-level, and distances to 200 meter depth iso-level are computed, based on GEBCO 1 minute resolution bathymetry 
data, to estimate bottom topographic feature and phase lag of each tide gauge.

The distances are computed following the algorithm by Wessel and Smith (1996).

Take distances to shoreline as an example. Firstly, each grid point in GEBCO bathymetry array is assigned a hierarchical level. Here those cells with positive depth are assigned index 1, those cells with 0 or negative depth are assigned index 0 . A coastline position with $0 \mathrm{~m}$ elevation is linearly interpolated using points with a positive bathymetry and the point with a negative bathymetry next to it. Once the coastline is determined, distances from a particular point to all coastline grid points are computed using Bowring formula (Bowring, 1983). Then a minimum distance is selected as its distance to the shoreline.

\subsection{Precision estimate}

Since no error estimation is available in IHO tidal data, the precision of amplitude is estimated for each tidal constituents. There are in total 11 tidal species in IHO tidal databank. The frequencies of these species are once per year, twice per year, once per month, twice per month, once per day, twice per day, three times per day, four times per day, six times per day, eight times per day and twelve times per day. The precision of each constituent in IHO was identified with the smallest amplitude of the constituent in each tidal species at each IHO station.

\subsection{Data transformation}


The original IHO tidal data is a text-based file. It is divided into individual tide gauges with tidal constituents in each row, and amplitude and phase in columns. The data were transformed into a netcdf file for convenience. Each tidal measurement is tabulated as a row. Its station name, coordinate, amplitude, phase, frequency, categories, characteristic length scale, and other information are listed as columns. The defined characteristic length scale, categories and distance to iso-levels are also available in the netcdf file. The netcdf file is then imported into a Matlab Graphical User Interface (GUI) to edit the data more efficiently. An example of the GUI is in figure 7.

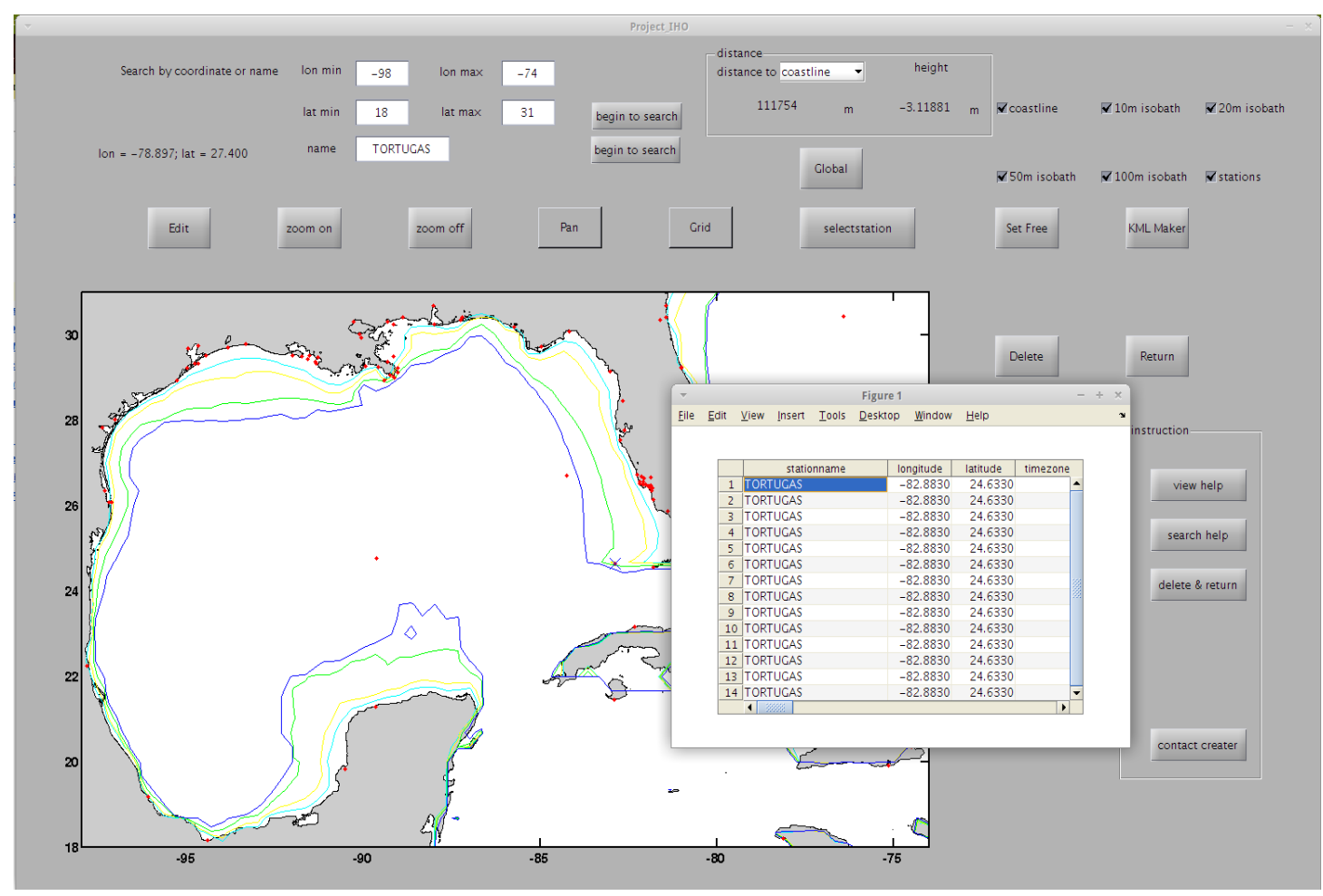

Figure 7. Matlab GUI created for editing IHO data.

The GUI uses GEBCO 1 minute resolution bathymetry data for its land-sea boundary. It has several functions that can make the editing more efficient and precise: Pan, Zoom 
or choose domain directly by entering the boundary coordinates; search tide gauge using its name; show information of a chosen tide gauge in a table; select and add a delete mark to an unwanted station.

\subsection{Harmonic Analysis}

Harmonic analysis of tides is based upon an assumption that the undulation of tides can be expressed as the sum of a series of harmonic terms related to astronomical conditions. Each term is known as a tidal constituent. Harmonic prediction is accomplished by reuniting the tidal consituents. As mentioned by Pawlowics et al. (2002), several shortcomings exist in classic Harmonic Analysis. The first shortcoming is that the nodal cycle correction is ignored. Nodal cycle correction was invented by Doodson. Because of the difference between the periods of the eclipitic and lunar orbit, one node on the moon takes about 18.6 years to return to the same position. The second shortcoming is that classic Harmonic Analysis gives no information about the quality of the resulting amplitude and phase. The third shortcoming is that, in shallow region, the dynamic of tides is not entirely due to the astronomical forcing. As a result, classic harmonic analysis is not the right response.

T_tide, a matlab routine package, which is developed by Pawlowics et al. (2002), overcomes the above shortcomings, and is used in this study to analysis SSH time series. It adds nodal modulation to harmonic analysis algorithm, provides error bar, and allows 
the user to add additional shallow water constituents to take account for the specific river flow condition. 


\section{Chapter 3: Results}

The IHO tidal data base, comprised of 4131 stations, provides adequate global coverage. Although our focus is in shallow water regions where shallow water tidal constituents are significant, only four major constituents $\mathrm{M} 2, \mathrm{~S} 2, \mathrm{~K} 1, \mathrm{O} 1$ are used in the following comparisons. The reason is, as shown in figure 8 , over $50 \%$ tidal stations in IHO data base have less than 9 constituents available, most of which have a distance to coastline less than $2000 \mathrm{~m}$. Since shallow water tidal constituents are not available for most stations in IHO data base, only M2 S2 K1 O1 are used for comparison in this study. 

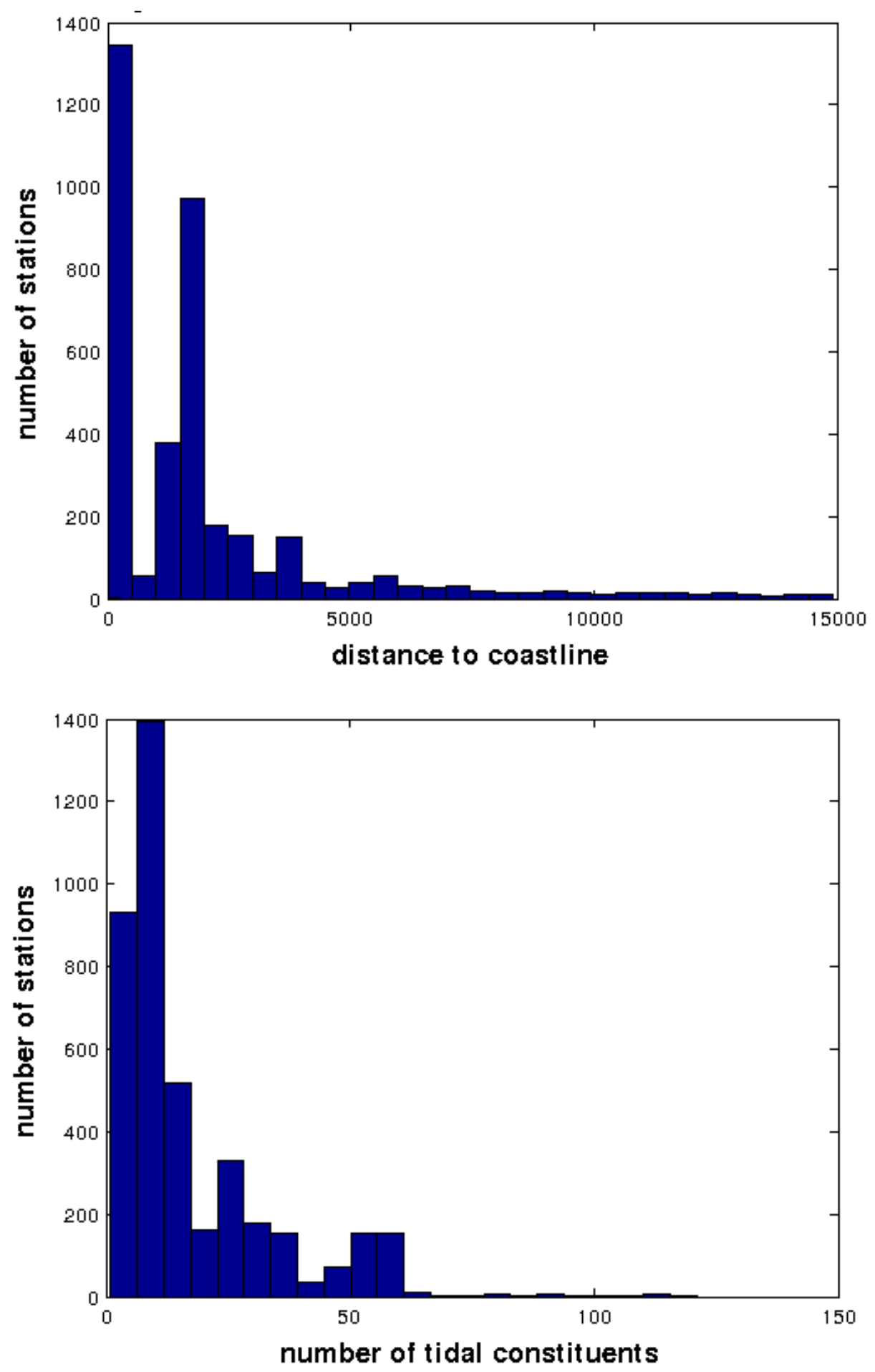

Figure 8. Top: Histogram of IHO station distribution on distance to coastline. Bottom: Histogram of IHO station distribution on number of tidal constituents. 


\subsection{GLOSS, IHO, OTIS pair wise comparison}

In this study, OTIS model output is used to access model predictability at locations of IHO stations, and test our hypothesizes by using defined characteristic length scale, categories and distance to iso-levels.

Figure 9 shows the M2 tidal constituent amplitude differences between IHO data and OTIS output versus the defined characteristic length scale, the stations with category "open ocean" are excluded. The differences ranges from $10^{-4} \mathrm{~m}$ to several meters. However, no obvious trend can be found. S2, K1, O1 tidal constituents shares similar pattern as M2.

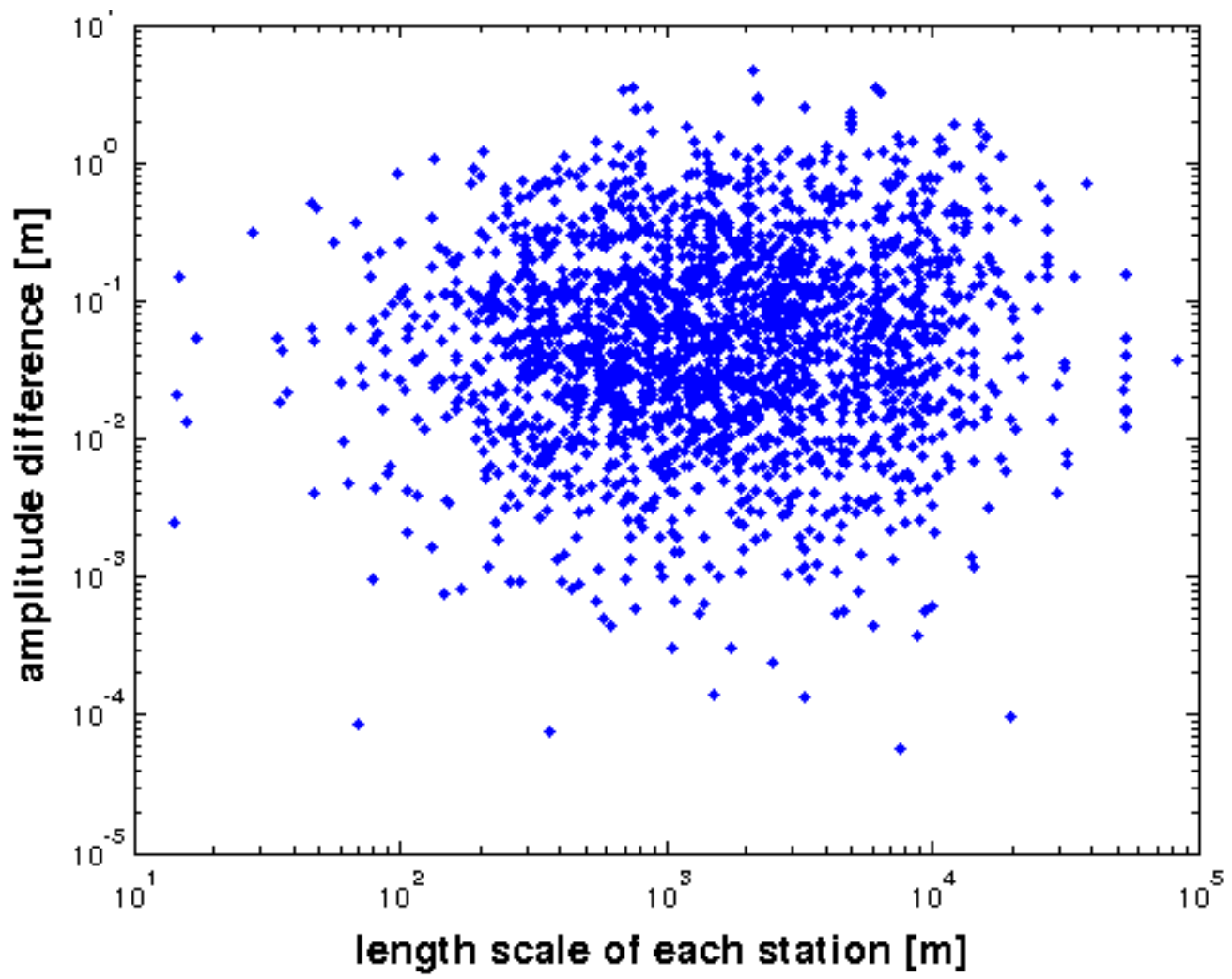

Figure 9. M2 amplitude difference between IHO data and OTIS output vs length scale. 
Figure 10 shows the M2 amplitude from IHO database versus that from OTIS output. 1699 stations are categorized as "open ocean" stations. 2432 stations are not categorized as "open ocean" stations. The amplitude from IHO database and OTIS model output lies in a band close to the 1:1 line. A closer look reveals that "open ocean" the stations with category "open ocean" are less scattered than those without "open ocean". The coefficient of determination $\mathrm{R}^{2}$ equals to 0.9983 for open ocean stations and it equals to 0.9941 for coastal stations. This implies that data from stations, which distribute further offshore, agrees more with model output than those, which distribute closer to coastline. What's more, the close to $1 \mathrm{R}^{2}$ value implies that the scattering is due to a small number of stations with large amplitude differences. S2, K1, O1 show analogous results. 

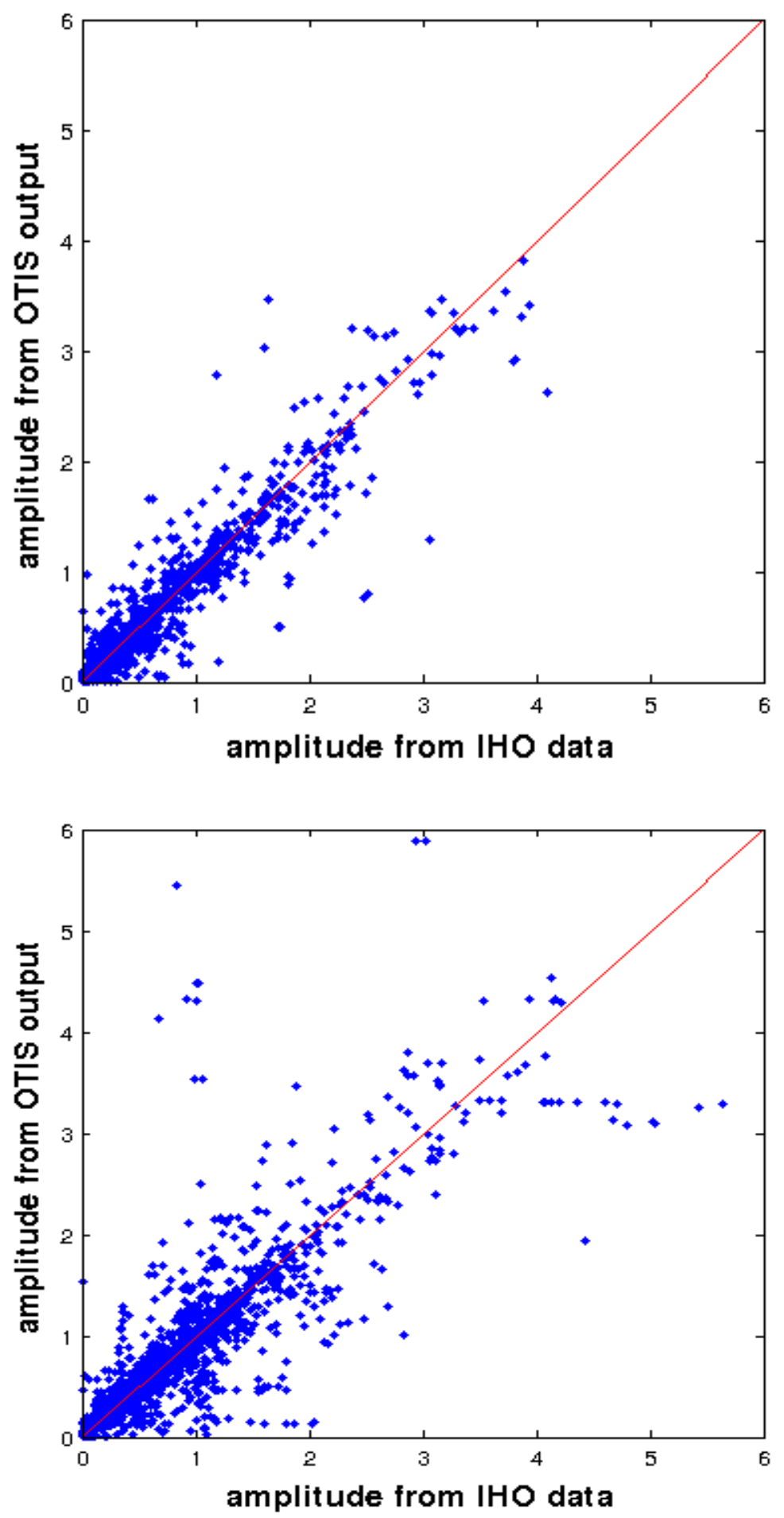

Figure 10. M2 amplitude from OTIS output vs IHO data. Top: stations categorized "open ocean". Bottom:

stations that are not "open ocean". 
Figure 11 shows the M2 amplitude differences between IHO data and OTIS result versus the distance to $200 \mathrm{~m}$ isobaths in log scale. Stations with depth larger than $200 \mathrm{~m}$ are excluded in this comparison. The result shows a increasing number of stations with both larger distance to $200 \mathrm{~m}$ isobaths and larger amplitude differences. Because $200 \mathrm{~m}$ isobaths is tens of thousands of meters offshore in most part of the globe, IHO minus OTIS error is larger at stations closer to the coast. This figure reinforces the statement that the tide prediction capability is relatively inferior in coastal regions comparing to the relative accurate deep ocean predictions.

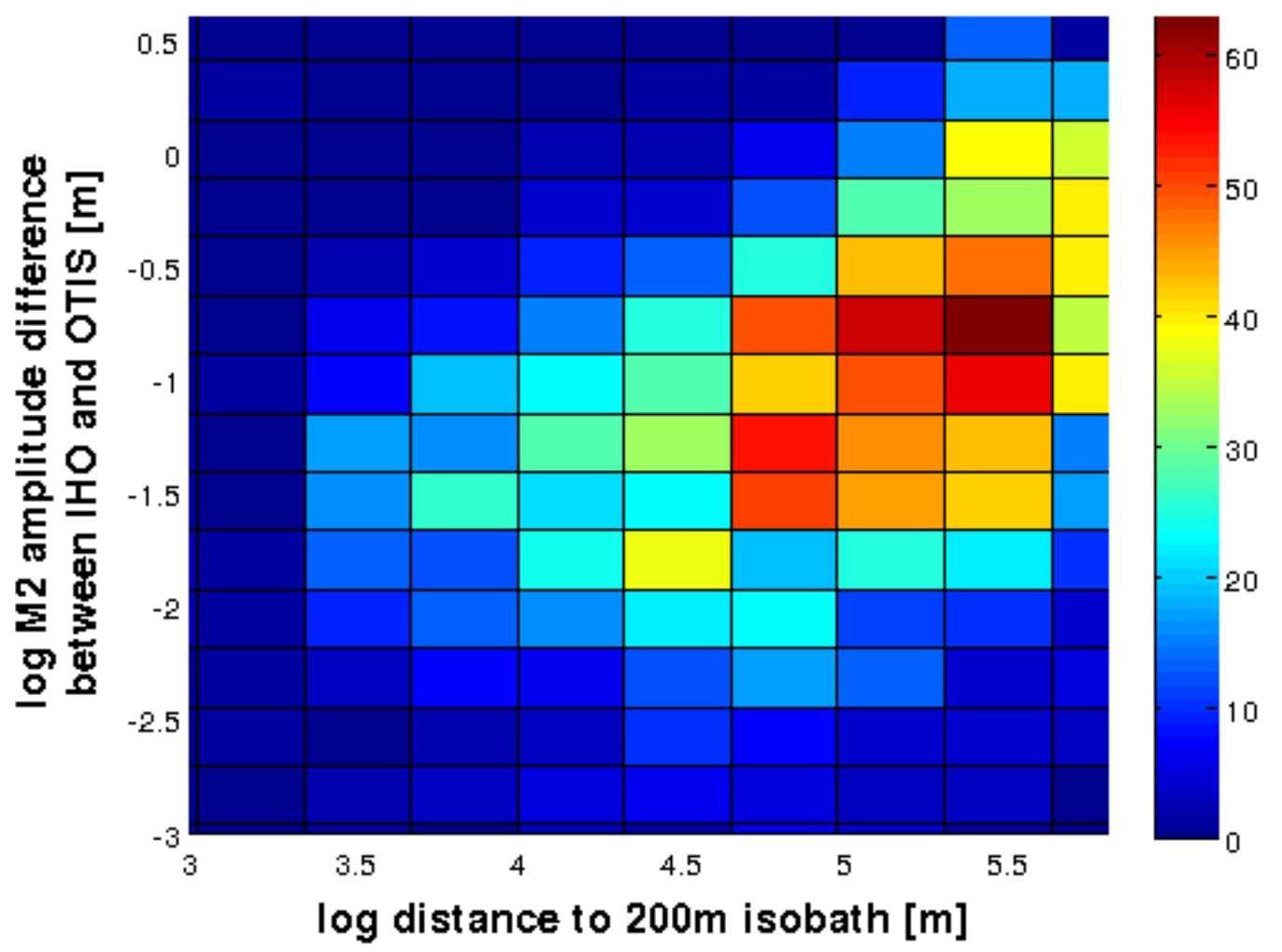

Figure 11. Number of tide gauges: amplitude difference vs distance to $200 \mathrm{~m}$ isobaths.

As a reliable data source, GLOSS tidal data is used to estimate the unknown 
precision and accuracy of IHO data. Figure 12 shows the distribution of characteristic length scale of IHO and GLOSS tidal stations. The stations, which are categorized "open ocean", are excluded for convenience. In IHO database, as shown in the top figure of figure 8 , for stations with length scale less than $20 \mathrm{~km}$, over $59 \%$ stations have length scales less than $2000 \mathrm{~m}$ and over $82 \%$ stations have length scales less than $5000 \mathrm{~m}$ which means that most IHO stations are located in regions surrounded by complicated topographic feature. In GLOSS database, as shown in the bottom figure of figure 12, the distribution of characteristic length scale is analogous to that of IHO, most stations have length scales less than $2000 \mathrm{~m}$, except that the stations with length scale over $3000 \mathrm{~m}$ have a slightly higher percentage than IHO data. 

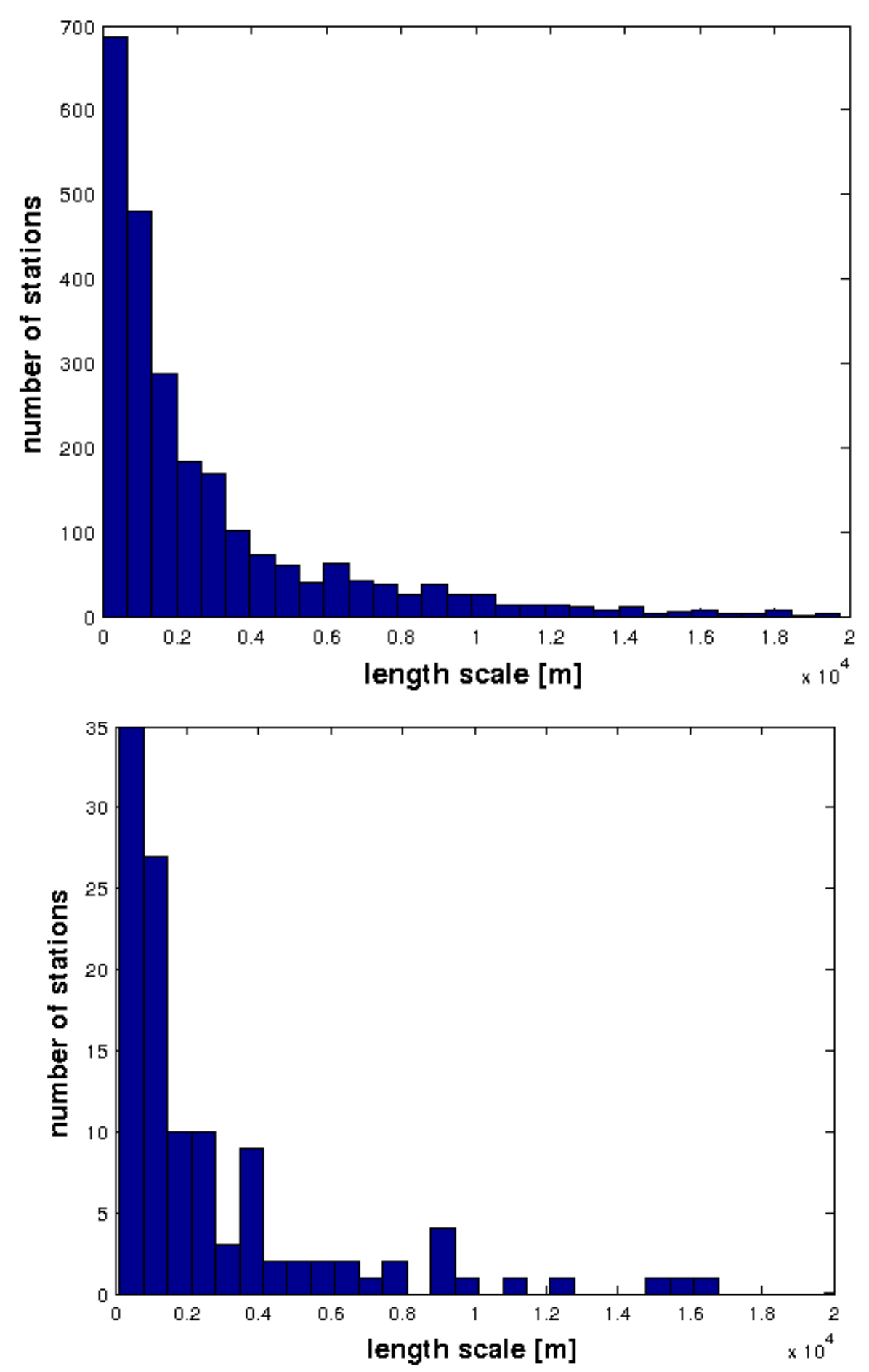

Figure 12. Histogram of station distribution on length scale. Top: IHO stations. Bottom: GLOSS stations.

RMS misfit among OTIS model output, IHO data and GLOSS data has been 
computed for four major tidal constituents: $\mathrm{M} 2, \mathrm{~S} 2, \mathrm{~K} 1, \mathrm{O} 1$. The result is shown in table 5, table 6 , table 7. In table 5, the RMS errors between OTIS output and IHO data for M2, $\mathrm{S} 2, \mathrm{~K} 1, \mathrm{O} 1$ are $31.73 \mathrm{~cm}, 36.76 \mathrm{~cm}, 12.97 \mathrm{~cm}, 29.00 \mathrm{~cm}$, respectively. The RMS errors between OTIS output and GLOSS data for M2, S2, K1, O1 are $16.98 \mathrm{~cm}, 20.80 \mathrm{~cm}, 3.37$ $\mathrm{cm}, 2.83 \mathrm{~cm}$, respectively. The RMS errors between OTIS output and duplicates stations in both IHO and GLOSS data base for M2, S2, K1, O1 are $18.61 \mathrm{~cm}, 23.98 \mathrm{~cm}, 3.38 \mathrm{~cm}$, $2.95 \mathrm{~cm}$, respectively. OTIS model output fits GLOSS data much better than IHO data for all four tidal constituents. The largest misfit is that of S2, the second largest misfit is that of M2. The model output fits the diurnal tidal species much better than semi-diurnals due to the longer period of diurnal tides. What's more, the model fit of duplicate stations which exist both in IHO and GLOSS is much better than that of only IHO stations. And the fit of duplicate stations is close to that for GLOSS stations. This can be explained, on the one hand, by the high percentage duplicate stations in GLOSS data base. Over 80\% GLOSS stations are also found in the IHO database. The RMS misfit of duplicate stations between IHO and GLOSS is small for all four tidal constituents and the relative differences of duplicate stations for all four tidal constituents are less than $16 \%$, as shown in table 6 and table 7. On the other hand, the quality of IHO data varies. IHO data is collected from various sources including long-term tidal stations, bottom pressure sensor, and short-term water level measurements, e.g. depth sounding. We believe that the quality of long-term records should be better than that of short-term records. In other 
words, long-term, well documented tidal records should have smaller tidal amplitude differences comparing to those short-term tidal records.

Table 5. RMS misfit: TPXO7.2 output vs IHO stations, GLOSS stations, GLOSS duplicate stations.

\begin{tabular}{lllll}
\hline RMS error(cm) & M2 & S2 & K1 & O1 \\
\hline IHO data & 31.73 & 36.76 & 12.97 & 29.00 \\
GLOSS data* & 16.98 & 20.80 & 3.37 & 2.83 \\
GLOSS & 18.61 & 23.98 & 3.38 & 2.95 \\
duplicates** & & & & \\
\hline
\end{tabular}

*234 GLOSS stations with valid OTIS output.

**189 duplicates with valid OTIS output.

Table 6. relative differences: GLOSS duplicate stations vs GLOSS stations.

\begin{tabular}{lllll}
\hline relative error & M2 & S2 & K1 & O1 \\
\hline GLOSS & 0.062 & 0.1143 & 0.0885 & 0.1531 \\
duplicates** & & & & \\
\hline
\end{tabular}

**198 duplicates. 
Table 7. RMS misfit: GLOSS duplicate stations vs GLOSS stations.

\begin{tabular}{lllll}
\hline RMS error(cm) & M2 & S2 & K1 & O1 \\
\hline GLOSS & 16.51 & 7.48 & 2.38 & 2.24 \\
duplicates** & & & & \\
\hline
\end{tabular}

**198 duplicates.

By harmonically analyzing time series from GLOSS data with different length of record (LOR), the LOR can be determined for duplicate stations in IHO data base. Firstly, time series from duplicate stations with LOR equals to two weeks, three weeks, four weeks and one year has been harmonically analyzed to get harmonic constants and error bars by using matlab routine t_tide. The errors are due to instrumental errors and non-tidal residuals. and are in a descending order as the LOR increases. Secondly, the amplitude differences for M2, K1 tidal constituents have been computed by taking the absolute values of amplitude differences between the amplitude in IHO data base and the amplitude obtained by harmonically analyzing one year time series from GLOSS stations. Thirdly, comparisons have been made to see which error interval the amplitude differences lie in. Then the LOR can be estimated based on the LOR of the error interval boundaries. Figure 13 shows the resulted M2, K1 comparisons of station Santa Cruz Galapagos Island which locates at $51.8583^{\circ} \mathrm{N}, 176.635^{\circ} \mathrm{W}$. The $\mathrm{M} 2$ and $\mathrm{K} 1$ amplitude differences both lie between four weeks and one year. Although the confidence interval 
does not continuously increase as the LOR decreases, it is still clear that this station is consistent with a LOR shorter than one year, but longer than four weeks.
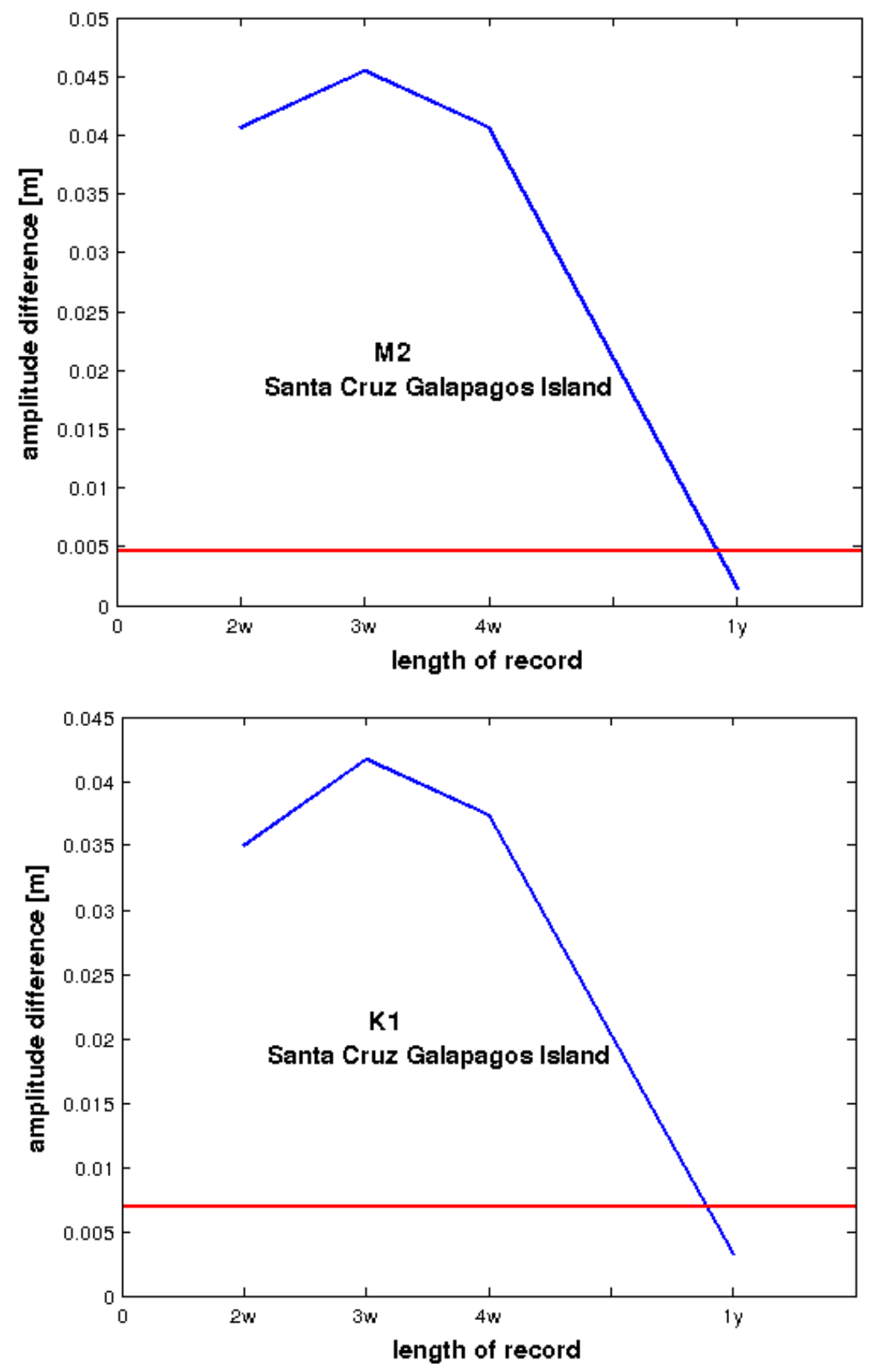

Figure 13. Length of record comparisons. Blue line is the error resulted from harmonically analyzing different length of time series. The time length is shown on the $\mathrm{x}$ axis. Red line is the amplitude difference. 
Results of comparisons between M2 and K1 are slightly different. As a result, the boundaries for each time interval can be determined. The result shows that approximately $61 \%$ to $82 \%$ stations in IHO data base have LOR between one month and one year. $9 \%$ to $17 \%$ stations have LOR between half a month and one month. Less than $3 \%$ stations apparently have LOR less than half a month.

\subsection{Distribution analysis}

The probability distributions of amplitude differences between OTIS model output and IHO tidal data have been computed for the four major constituents: M2, S2, K1, O1. Figure 14 shows the M2 amplitude differences distribution globally. Figure 15 shows the relative M2 amplitude differences distribution globally. S2, K1, O1 tidal constituents have analogous global feature as M2. The empirical distribution of the data difference is asymmetric around the origin. Three theoretical distributions are compared to test which one best fits the data: 1). Gaussian distribution. 2). Laplace (double exponential) distribution. 3). Cauchy distribution. All scale parameters for known distributions are computed based on the 25 and 75 percentile of the empirical distribution of the data. A detailed list of scale parameters of Laplace and Cauchy distribution is shown in table 8 . Both Laplace and Cauchy distribution have better fit to the high peak and flat tails. However, a closer look at the cumulative distribution plot in figure 14 bottom and 15 bottom shows that Cauchy distribution fits the empirical distribution best. Although this 
cannot be verified by applying Kolmogorov-Smirnov test, the p-value for Cauchy distribution is largest. As a result, we will still use Cauchy distribution in the following analysis as the best fit of M2 amplitude differences distribution.

Table 8. scale parameters of Laplace and Cauchy distribution.

\begin{tabular}{lllll}
\hline & \multicolumn{2}{c}{ scale parameter for absolute error } & \multicolumn{2}{c}{ scale parameter for relative error } \\
\cline { 2 - 5 } & Laplace & Cauchy & Laplace & Cauchy \\
\hline M2 & 0.0877 & 0.0608 & 0.1727 & 0.1197 \\
S2 & 0.0414 & 0.0287 & 0.2387 & 0.1655 \\
K1 & 0.0276 & 0.0191 & 0.1736 & 0.1203 \\
O1 & 0.0219 & 0.0152 & 0.2016 & 0.1389 \\
\hline
\end{tabular}



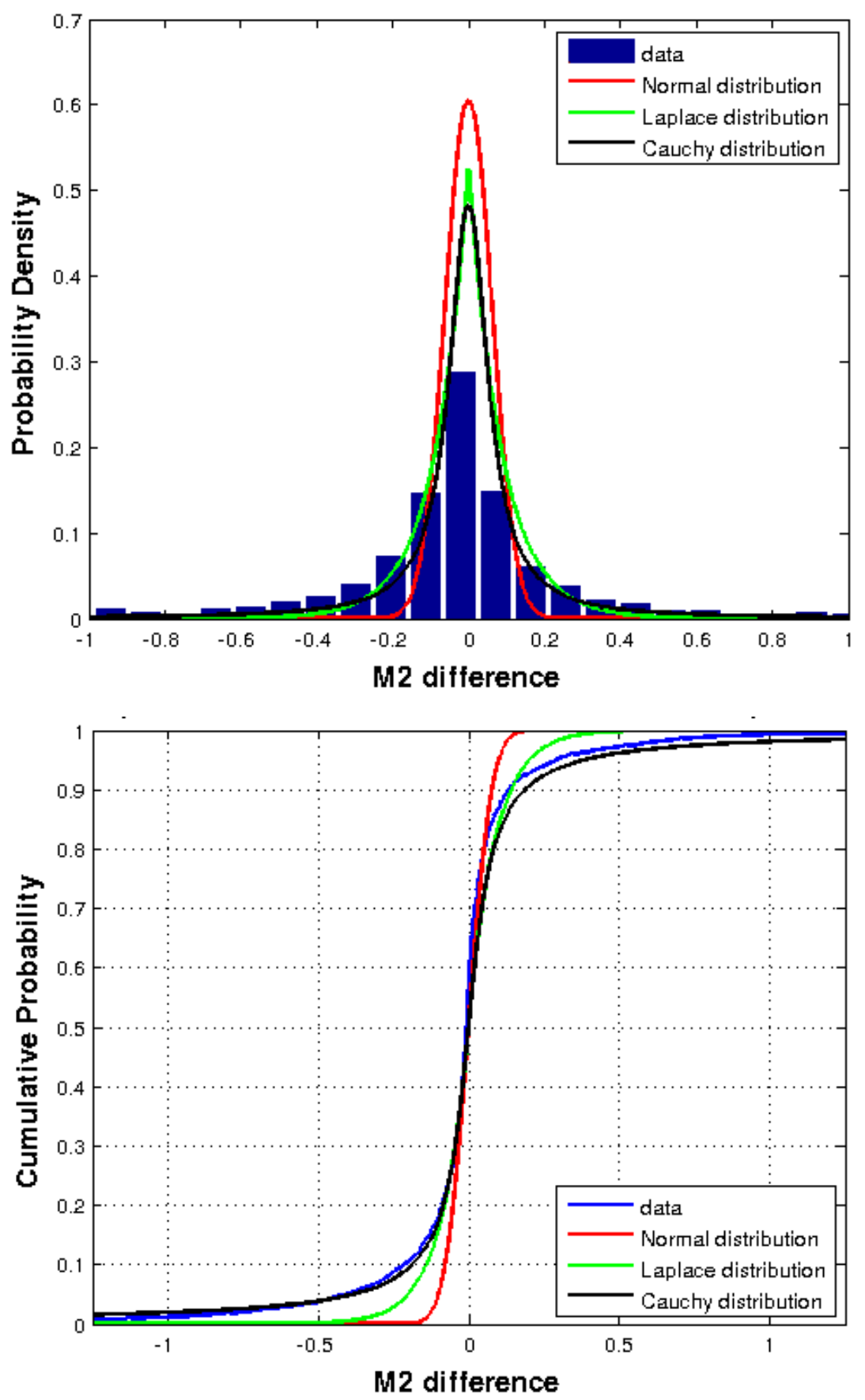

Figure 14. Top: Histogram of M2 relative error distribution and probability distribution plot. Bottom:

Cumulative distribution plot. Red line is Gaussian distribution, green line is Laplace distribution, black line is Cauchy distribution. 

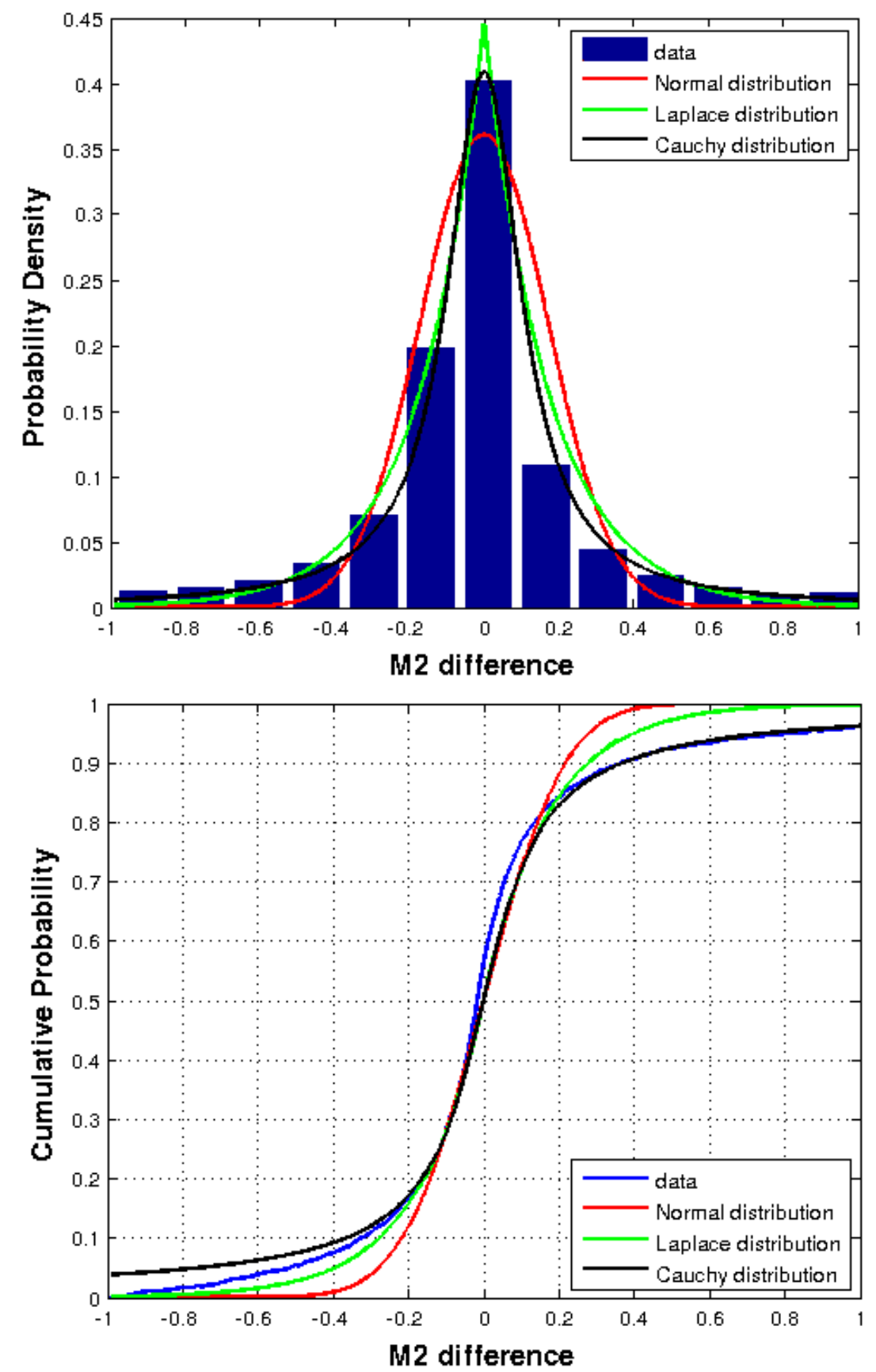

Figure 15. Top: Histogram of M2 relative error distribution and probability distribution plot. Bottom

Cumulative distribution plot. Red line is Gaussian distribution, green line is Laplace distribution, black line

is Cauchy distribution.

By taking the $96 \%, 90 \%, 85 \%$ probability intervals of Cauchy distribution, 61,270 , 
485 stations with relative M2 differences outside of the corresponding interval are selected, respectively, and shown as red dots in figure 16. It is clearly shown that most stations with large M2 amplitude relative errors distribute either close to the coastline or surrounded by complex land configuration. However, some stations with large relative amplitude error locate either in the open ocean, e.g. stations in the Pacific Ocean, or near relatively simple coastal configuration, e.g. stations near the coastline of South America. This can be explained by the small M2 amplitudes of these stations shown in the top of figure 17. Even though, the absolute M2 amplitude differences between IHO and OTIS at the locations of these stations are small as shown in the middle of figure 18, the large error ratio makes the relative $\mathrm{M} 2$ amplitude difference large. 

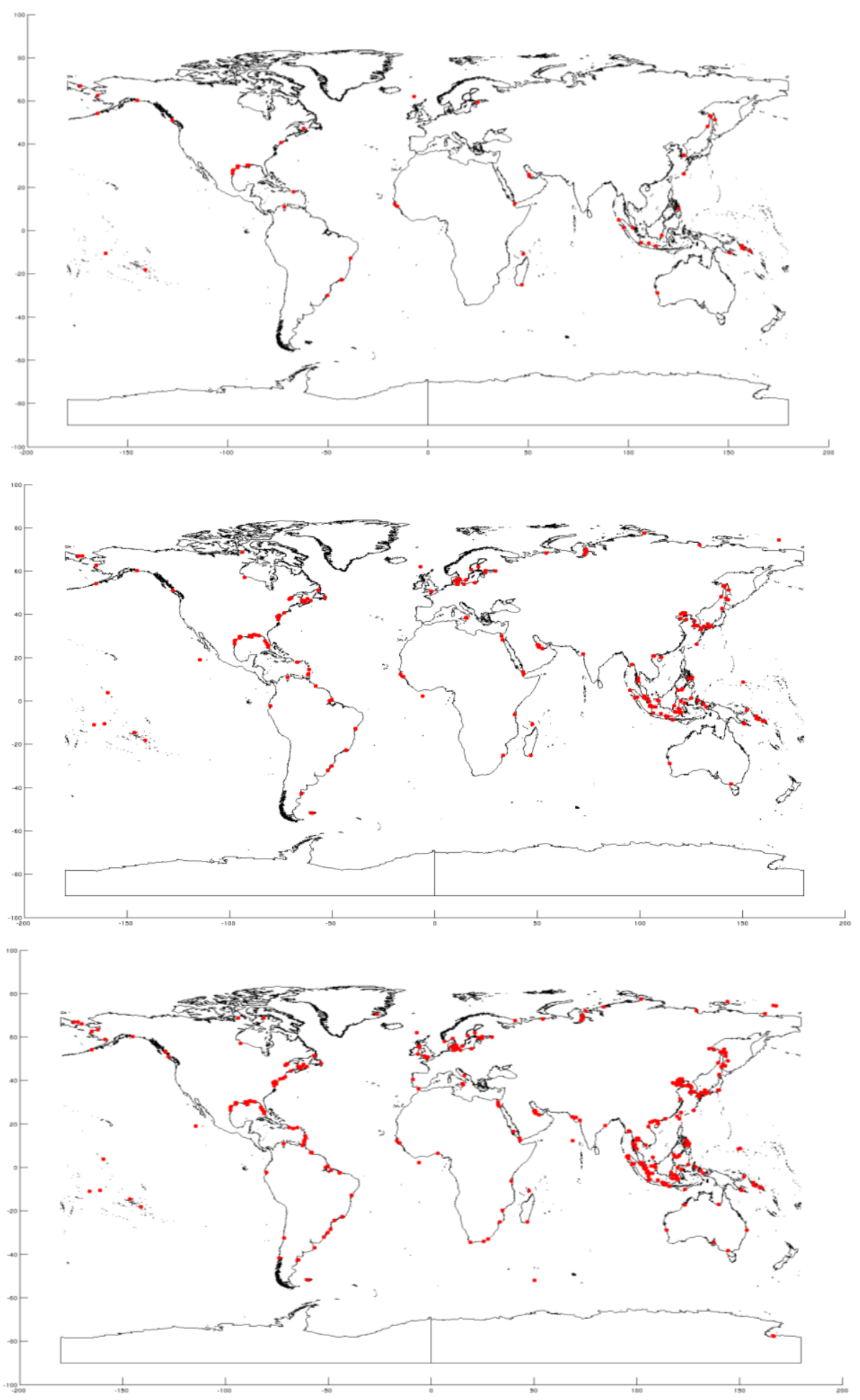

Figure 16. Locations of large error stations (outliers of top: $96 \%$ confidence interval, middle: $90 \%$ confidence interval, bottom: $85 \%$ confidence interval), shown in red dot. 


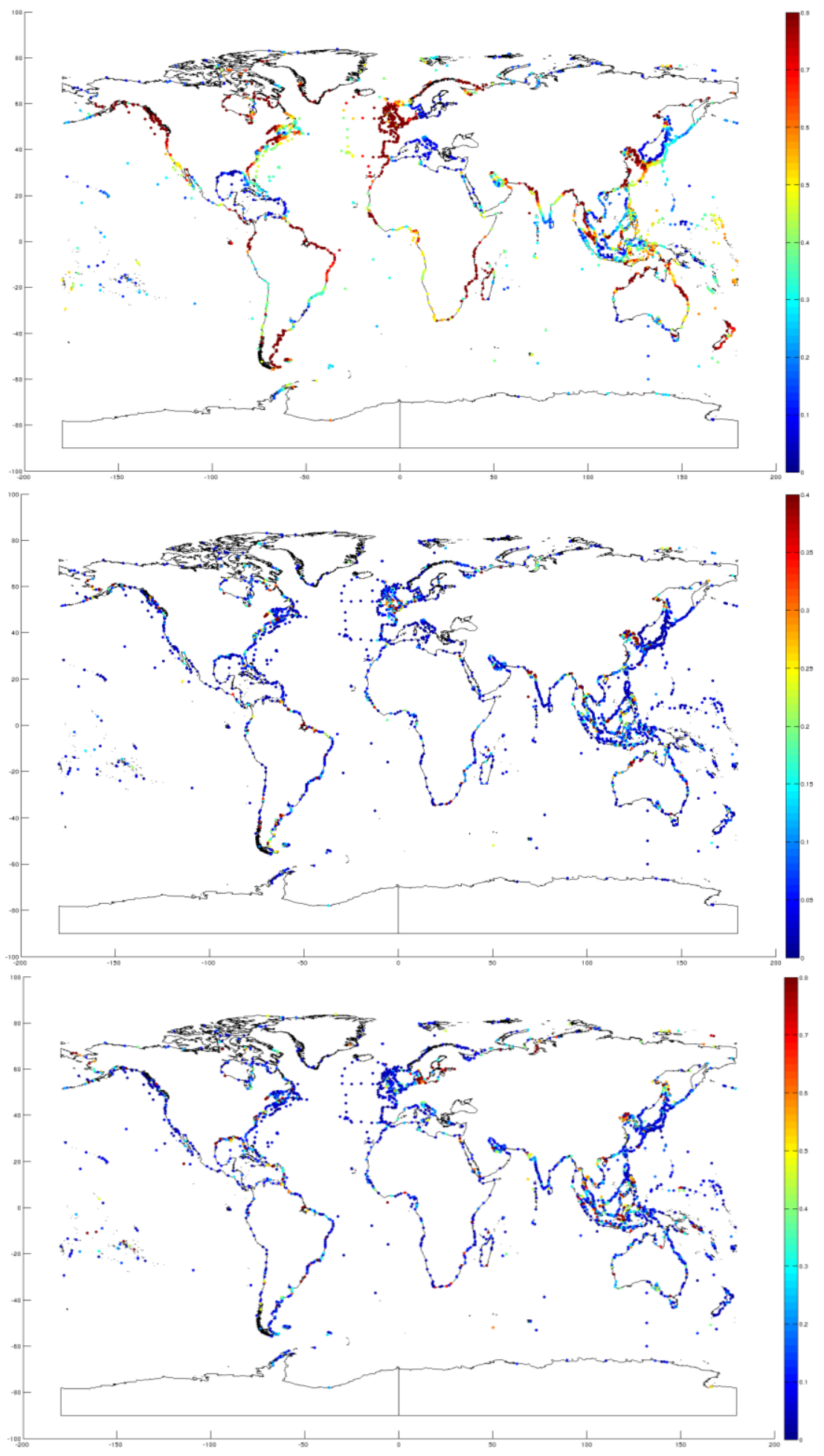

Figure 17. Top: M2 amplitude of IHO stations. Middle: absolute M2 amplitude difference between IHO and OTIS. Bottom: relative M2 amplitude difference between IHO and OTIS. 


\section{Chapter 4: Summary and Conclusions}

Tides are periodic movements of the sea surface primarily due to astronomical forcing exerted by the sun and the moon. To estimate and predict the tide, numerical modeling has been used and improved in the last century. Although tidal estimation in the open ocean is adequately accurate, it is still hard to get accurate results from tidal models in shallow regions due to the surrounding complex geomorphology, bottom bathymetry, river water, man-made harbors, etc. Since modern tidal models are intensively data dependent, IHO data base with thousands of coastal tidal stations is extremely valuable for today's coastal tidal study. This study has two major objectives: 1. test the quality and accuracy of IHO data; 2. examine the characteristics of stations with large error.

The first objective is achieved through pair wise comparisons among IHO data, GLOSS data and OTIS model output addressed in Chapter 3.1. The result shows that most stations in IHO data base are coastal stations located in complex topographies. IHO minus OTIS error is larger at stations closer to the coast. The RMS misfit between Model output and IHO data varies significantly. Stations with long-term, well documented records have smaller RMS misfits, e.g. duplicate stations in GLOSS data base have analogous RMS misfits as the complete GLOSS data base does. A rough LOR estimation has been made based on comparing the results of harmonically analyzing time series of stations in GLOSS data base with different LORs and M2, K1 amplitude differences 
between IHO and GLOSS. The result shows that approximately $61 \%$ to $82 \%$ stations in IHO data base have LOR between one month and one year; $9 \%$ to $17 \%$ stations have LOR between one month and half a month; less than 3\% stations have LOR less than half a month. However, the number of duplicate stations is a small percentage in IHO database and it is sparse around the globe. This estimation is valid only for well documented stations.

The second objective is achieved through analysis of the probability of distribution by using the relative amplitude differences between IHO data and OTIS model output. It has been shown that the relative amplitude differences of the four major tidal constituents follows the Cauchy distribution. By analyzing outliers of relative M2 amplitude difference and comparing with the actual amplitude and absolute M2 amplitude differences, it can be seen that most stations with large errors either locate in complex coastal regions or have relatively small amplitude comparing to the misfit from tidal model.

Three hypotheses were tested in this study. Firstly, it is surprising that the characteristic length scale shows no clear relationship with either IHO-GLOSS or IHO-OTIS differences. One possible reason is the coarse bathymetry resolution used in tidal model. Because the quality control of each tidal station in IHO data base is based on high resolution Google Earth image, most stations with small characteristic length scale either distribute so far inland that no valid model outputs exist or distribute in regions so 
complex that the bathymetry data used in OTIS cannot resolve this detailed topographic complexity.

The categorization of IHO tidal stations that was made through Google Earth can partially identify the geomorphologic feature of the vicinity of tidal stations. A rough result can be seen from the OTIS-IHO M2 amplitude differences. Stations without category "open ocean" have M2 amplitude differences in a larger range that those with "open ocean". However, this detailed description for topographies around stations cannot be represented by the bathymetry data in tidal models.

The precisions estimated for each tidal species cannot represent the actual precisions of each station. The only relationship which can be found is the larger number of constituents one station has, the smaller the precisions are for the constituents of this station. However, no evidence shows that the more tidal constituents one station has, the better quality the record from this station is. As a result, the precisions we estimated cannot represent the actual instrumental and non-instrumental error for stations in IHO.

Last but not least, this study documents the error in the TPXO7.2 tidal model relative to a large set of coastal tidal data. The spatial distribution of errors, and their severity (shown in figure 16) identifies regions where tide models require improvement and adds to the more limited comparisons in Ray et al. (2011). The analysis also demonstrates the non-Gaussian character of the errors, which suggests that further improvements in tidal modeling will require advances in data assimilation which are robust to non-Gaussian 
data error. The good comparison of IHO with duplicate GLOSS stations shows that, as far as can be determined, IHO data are reliable and ought to be used in improving coastal tide models. 


\section{References}

Andersen, O. B., Egbert, G. D., Erofeeva, S. Y., Ray, R. D. (2006). Mapping nonlinear shallow tides: a look at the past and future. Ocean Dynamics, Volume 56, Number 5-6, 416-429, doi:10.1007/s10236-006-0060-7.

Bazilchuk, N. (2006). The Greatest Map on Earth. Conservation In Practice, 7(3), 5-36.

Bennett, A. F. (1992). Inverse Methods in Physical Oceanography. Monographs on Mechanics and Applied Mathematics. Cambridge University Press, 346 pp., reprinted 1999, 2003.

Blain, C.A., Preller, R.H., Rivera, A.P. (2002). Tidal prediction using the advanced circulation model (ADCIRC) and a relocatable PC-based system. Oceanography, 15 (1), 77-87.

Bowring, B. R. (1983). Bulletin Géodésique. Journal of Geodesy, Volume 57, 374-381.

Brown, A. H. (2009). Columbia River: riding the high water. Professional MarinerJournal of the Maritime Industry, Issue 121.

Doodson, A. T. (1921). Harmonic development of the tide-generating potential. Proceedings of the Royal Society of London, A100, 305-329.

Doodson, A. T., \& Warburg, H. D. (1941). Admiralty manual of tides. H. M. Stationery Off, 270pp.

Egbert, G. D. (1997). Tidal data inversion: Interpolation and inference. Progress of 
Oceanography, 40,53-80.

Egbert, G. D., Bennett, A. F., Foreman, M. G. G. (1994). TOPEX/POSEIDON tides estimated using a global inverse model. Journal of Geophysical Research, 99(C12), 24821-24852, doi: 10.1029/94JC01894.

Egbert, G. D., \& Erofeeva, S.Y. (2002). Efficient inverse modeling of barotropic ocean tides. Journal of Atmospheric and Oceanic Technology, 19, 2, 183-204.

Friedrichs, C. T., \& Aubrey, D. G. (1994). Tidal propagation in strongly convergent channels. Journal of Geophysical Research, 99(C2), 3321-3336, doi: 10.1029/93 JC03219.

Fu, L., \& Cazenave, A. (2000). Satellite altimetry and earth sciences: a handbook of techniques and applications. Academic Press, 2000.

Green, G. (1838). On the Motion of Waves in a Variable Canal of Small Width and Depth. Transactions of the Cambridge Philosophical Society 6: 457-62. See Ferrers 1871, 223-230.

Harris, R. A. (1901). Manual of Tides. U.S. Government Printing Office, 1901. 420pp. Hendershott, M. (1972). The effects of solid Earth deformation on global ocean tides. Geophysical Journal Royal Astronmical Society, 29, 389-403.

Jay, D. A. (1991). Green's law revisited: Tidal long-wave propagation in channels with strong topography. Journal of Geophysical Research, 96(C11), 20585-20598.

Lanzoni, S., \& Seminara, G. (1998). On tide propagation in convergent estuaries. Journal 
of Geophysical Research, 103(C13), 30793-30812.

Padman, L. (2005) Tide Model Driver (TMD) Manual. Available from $\mathrm{ftp}: / / \mathrm{ftp}$. esr.org/pub/datasets/tmd/tmd toolbox.zip

Lefevre F., Le Provost, C., Lyard, F. H. (2000). How can we improve a global ocean tide model at a regional scale? A test on the Yellow Sea and the East China Sea. Journal of Geophysical Research, 105, C4, 8707-8725.

Lyard, F., Lefevre, F., Letellier, T., Franci, O. (2006). Modeling the global ocean tides: modern insights from FES2004. Ocean Dynamics 56, 394-415, doi: 10.1007/s10236-006-0086-X.

Merrifield, M., Aarup, T., Allen, A., Aman, A., Caldwell, P., Bradshaw, E., Fernandes, R., Hayashibara, H., Hernandez, F., Kilonsky, B., Martin Miguez, B., Mitchum, G., Pérez Gómez, B., Rickards, L., Rosen, D., Schöne, T., Szabados, M., Testut, L., Woodworth, P., Wöppelmann, G., Zavala, J., 2009. The Global Sea Level Observing System (GLOSS).

Parker, B. B., Davies, A. M., Xing, J. (1999). Tidal height and current prediction, in Coastal Ocean Prediction. Coastal Estuarine Study, vol. 56, 277-327, AGU, Washington, D. C., doi: 10.1029/CE056p0277.

Pawlowicz, R., Beardsley B., Lentz, S. (2002) Classical tidal harmonic analysis including error estimates in MATLAB using T_TIDE. Computer and Geosciences 28, 929-937. Posey, P. G., Allard, R. A., Preller, R. H., Dawson, G. M. (2008). Validation of the Global 
Relocatable Tide/Surge Model PCTides. Journal of Atmospheric and Oceanic Technology, 2008, 25, 755-775.

Pugh, D. T. (1987). Tides, surges, and mean sea-level. John Wiley \& Sons, 1987, 472pp.

Ray, R. D., Rowlands, D. D., Egbert, G. D. (2003). Tidal Models in a New Era of Satellite Gravimetry. Space Science Reviews, v. 108, Issue 1, 271-282.

Ray, R. D., Egbert, G. D., Erofeeva, S. Y. (2011). Tide predictions in shelf and coastal waters: status and prospects. Coastal Altimetry, Springer-Verlag, 191-216.

Roy, A. E. (1978). Orbital Motion. Bistol: Adam Hilger, 489pp.

Segar, D. A. (1998). Introduction to ocean sciences. Wadsworth Publishing, 497pp.

Schureman, P. (1976). Manual of Harmonic Analysis and Prediction of Tides. United States Government Printing Office, Washington, 317pp.

Smart, W. M. (1940). Spherical Astronomy. Cambridge University Press, 430pp.

Wessel, P., \& Smith, W. H. F. (1996). A Global Self-consistent, Hierarchical, High-resolution Shoreline Database. Journal of Geophysical Research, 101,8741-8743. 